\title{
RELEASES FROM THE COOLING WATER SYSTEM IN THE WASTE TANK FARM (U)
}

by W.C. Perkins

Westinghouse Savannah River Company

Savannah River Site

Aiken, South Carolina 29808

Other Authors:

C. R. Lux

(WSRC)

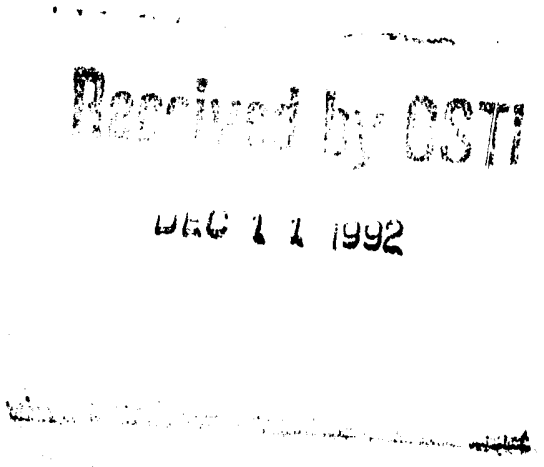

This paper was prepared in connection with work done under Contract No. DE-AC09-89SR18035 with the U. S. Department of Energy. By acceptance of this paper, the publisher and/or recipient acknowledges the U.S. Government's right to retain a nonexclusive, royalty-free license in and to any copyright covering this paper, along with the right to reproduce and to authorize others to reproduce all or part of the copyrighted paper. 


\section{DISCLAIMER}

This report was prepared as an account of work sponsored by an agency of the United States Government. Neither the United States Government nor any agency thereof, nor any of their employees, makes any warranty, express or implied, or assumes any legal liability or responsibility for the accuracy, completeness, or usefulness of any information, apparatus, product, or process disclosed, or represents that its use would not infringe privately owned rights. Reference herein to any specific commercial product, process, or service by trade name, trademark, manufacturer, or otherwise does not necessarily constitute or imply its endorsement, recommendation, or favoring by the United States Government or any agency thereof. The views and opinions of authors expressed herein do not necessarily state or reflect those of the United States Government or any agency thereof.

This report has been reproduced directly from the best available copy.

Available to DOE and DOE contractors from the Office of Scientific and Technical Information, P.O. Box 62, Oak Ridge, TN 37831; prices available from (615) 576-8401, FTS 626-8401.

Available to the public from the National Technical Information Service, U.S. Department of Commerce, 5285 Port Royal Rd, Springfield, VA 22161. 


CC: D. C. Richardson, 773-A *
G. T. Wright, 703-H
S. S. Cathey, 703-H
R. A. Scaggs, 703-H
B. L. Lewis, 703-H
W. L. Tamosaitis, 773-A
D. D. Walker, 773-A

TO : O. M. Ebra-Lima, 773-A TO: O. M. Ebra-Lima, 773-A
FROM: W. C. Perkins, 773-42Afted
C. R. Lux, 773-42A Nuclear Processes Safety Research section
W. S. Durant, 773-42A

K. W. Stephens, 773-42A

M. K. Gupta, 773-68A

M. J. Ades, 773-4 1A

P. D. d'Entremont, $703-\mathrm{H}$

S. M. Patel, 773-42A

M. L. Cowen, 773-42A

SRI Records (2)

January 27, 1992

RELEASES FROM THE COOLING-WATER SYSTEM IN THE WASTE TANK FARM (U)

\section{INTRODUCTION}

Recently, a cooling-water header broke in the H-Area Waste Tank farm, releasing contaminated water down a storm sewer that drains to the creek. A copy of the Occurrence Report is attached. As part of the follow-up on this incident, the NPSR Section was asked by Waste Management Technology to perform a probabilistic analysis of the following cases:

1. A large break in the header combined with a large break in a cooling coil inside a waste tank.

2. A large break in the header combined with a leak in a cooling coil inside a waste tank.

3. A large break in the header combined with a very small leak in a cooling coil inside a waste tank.

This report documents the results of the analysis of these cases.

\section{SUMMARY}

Calculated frequencies are 4E-07/year for Case 1, 1E-03/year for Case 2, and 2E-01/year for Case 3. The estimated maximum consequences (to an offsite individual) for the liquid releases in Cases 2 and 3 are 1.8E-05 Rem and 5.5E-06 Rem, respectively, and are within the envelope of the accident consequences in the Waste Tank Farm Safety Analysis Report (SAR, Ref. 1).

It is recommended that, because of the importance of this parameter to this analysis, the minimum times for responses to large breaks in the cooling water header or a cooling coil be made operational safety Requirements. As an alternative, an engineered solution, such as siphon breaks, should be installed to prevent siphoning.

* Introduction and summary only. 
WSRC-TR-91-562

\section{DISCUSSION}

\section{Incident Description}

At 5:45 PM on september 12, a low-cooling-water alarm was received from the surge tank in the East pump House in the H-Area Waste Tank Farm. (See Figures 1 to 5.) This alarm usually means a large leak has occurred somewhere in the system.

Suspecting a leak in the cooling-water header, Waste Management personnel found water coming up from an underground rupture of the supply header near the pump house. The occurrence Report (Attachment A) states that some of the cooling water flowed into a nearby storm sewer and entered the unmonitored storm water system. The leak site was excavated, and the rupture was patched. The system was returned to service on september 15.

The East Pump House supplies chromated cooling water to Waste Tanks 9 through 15 and 29 through 32 . (See Figure 2 and Attachrnent 2 , "Waste Tank Cooling systems".) A 625-gallon surge tank, shown in each of the Figures, pressurizes this cooling water system. This pressure prevents significant quantities of waste from entering this system in the event of a leak in a cooling coil in any of the tanks served. Loss of water from the system for any reason is made up automatically from the surge tank. It takes a relatively large leak to cause a low-cooling-water alarm there, because of the 625-galion capacity of the surge tank.

Description of a Hypothetical Accident (Case 1)

During the investigation of this incident, a hypothetical waste siphoning accident was proposed. If the header rupture that occurred in this incident were to occur at the same time as a major coil failure in a waste tank, raw waste conceivably could siphon from the tank and out through the header breach.

In the scenario, a "guillotine break" occurs in a cooling coil from an unidentified initiator. Such a break could leave an open 2 " coil under the surface of the waste in the tank. This has not happened in the history of the tank farms.

The header failure would rapidly deplete the water in the surge tank, depressurizing the cooling water system. Waste would then invade the cooling coils and recirculation piping. Siphoning of waste from the tank through the header is possible, because many of the waste tanks are at higher elevations than the pump house and much of the header piping.

Case 2 Description

This case combines a large header break with a coil leak. Coil leaks occur occasionally in waste tanks, particularly in the older H-Area tanks, but the leak rate is small' compared to the hypothetical break in Case 1 . 


\section{Case 2 Description (Continued)}

As in Case 1, the header failure would rapidly deplete the water in the surge tank, depressurizing the cooling water system. Waste would then invade the cooling coils and recirculation piping. Siphoning of waste from the tank through the header is possible, but at a slower rate than in Case 1.

Case 3 Description

Very small leaks in cooling coils are difficult to detect, so one could be present at almost any time. This case is identical to case 2 , except for the size of the hole in the cooling coil. The smaller hole would result in a slower waste release rate than in case 2.

\section{ANALYSIS}

The data required for this analysis include the frequencies of coil and header failures, their durations, their release rates, the radioactive composition of the waste released, and a model of the amount of a release that could reach the Savannah River.

\section{cooling water Header Failures}

In all three cases of this analysis, the frequency used for a large leak in the header that circulates the chromated cooling water is $2 \mathrm{E}-05 / \mathrm{hr}$, or about one per six years in F- and H-Areas. This value is taken from the Tank Farm SAR (Ref. I) and from the 200-Area Fault Tree Data Bank (Ref. 2).

In the SAR, a fault tree on page B-35 develops the header failure frequency (2E-05/hr) as part of a tree calculating "Failure to supply cooling Water" to a waste tank. The dominant causes are natural phenomena and piping failures.

The 200-Area Fault Tree Data Bank contains, prior to the recent $9 / 91$ failure, three failures in the 18-year period, 1973 to 1991. One of these releases occurred in H-Area in May 1973. The other two occurred in FArea; a large release through a one-half inch hole in the header was reported in May 1981. An F-Area header also ruptured in December of 1981.

Cooling water Header Repair

The duration of a release from the cooling water header is taken as three hours for this analysis. This three-hour value is based on an estimate (as to future performance) in the memo from WMT in Attachment 3 .

It took about three days to patch the cooling water header. The header was valved off much earlier, stopping the release. Total isolation of the tanks was achieved within eight hours (Attachment 1). For the purpose of this analysis, it is assumed that this valving occurred in about 24 hours. Current procedures require that the valve at each affected tank be closed as soon as a leak is discovered. Operators were alerted to a leak by the liquid-level monitor on the surge tank that pressurizes the cooling water 


\section{Cooling Water Header Repair (Continued)}

system and by an alarm that sounds when the surge tank is empty. In case of the proposed siphon of waste from a tank, operators would also be alerted by an alarm from the area radiation monitors, called VAMPS.

The time for response to a large break in the cooling water header is such an important parameter in this analysis, that it should be made an operational safety Requirement (OSR). That is, all tanks in a cooling system should be isolated from the system when a header leak occurs of sufficient size to cause pressure to be lost in the system. The OSR should also specify the minimum response time for this isolation. As an alternative, an engineered solution, such as a siphon break, could be provided to prevent siphoning.

Cnly a large header leak is included in this analysis. It is assumed that in case of a small header leak the cooling water system will not lose pressure, because of the 625-galion surge tank. (Its water level is checked once per shift; the tank is refilled as needed or in response to the low-level alarm.) Any concurrent coil leak then would leak cooling water into the waste tank, and no siphoning would be possible. A small header leak could release some contaminated cooling water, probably under the ground. Operation with the system depressurized was not considered in this analysis.

\section{Cooling Coil Failures}

In this analysis, a distinction is made between coil failures (the largest category, Case 1), coil leaks (Case 2), and small coil leaks. The coil failure is a hypothetical "guillotine" break causing a 2 " opening in the coil. No credible mechanism has been identified for such a break.

The frequency for coil leaks used in this analysis is about 0.12 per tank-year and is based on Tank Farm experience up to 1991. A iisting of tank service dates and of coil leaks through 1985 by tank is given in Appendix A of the SAR. Those data were updated to include more recent experience from Table WM-1 and the graph in Attachment 3. The result is 57 coil failures in 462 tank-years for those tanks where siphoning is possible.

Siphoning is not considered possible in Type IV tanks (17-24), because they have no cooling coils, nor in Tanks 1 through 12 because of their location.

The coil failure, proposed in the siphoning scenario, has not occurred in the Tank Farm. For all tanks with cooling coils, there have been a total of 138 coil leaks, but no such coil failures. (The older tanks at the bottom of the hili have experienced more leaks than the newer ones on the hill.) As a conservative approximation, the frequency of a coil failure was calculated from the frequency of experienced coil leaks $\left(0.12 / \mathrm{t}_{\mathrm{k}}-\mathrm{yr}\right)$ divided by 138 , the number of coil leaks experienced without a coil failure. The frequency used is $8.9 \mathrm{E}-04 /$ tank-year.

For the small coil leak (Case 3), the assumption is made in this analysis that this leak is so small (e.g. a "pinhole") that it is undetectable and always present. As a result then, the probability of such a leak is assumed to be one for the purposes of this analysis. 


\section{Cooling Coil Leak Duration}

For this analysis, the duration of a cooling coil leak is assumed to be seven days, based on the recommendation in Attachment 3. The cooling water system is pressurized so that cooling water leaks into the waste tank. Rapid detection of such a leak is not always possible, and it can take several days to determine that a leak exists and to locate which coil is leaking. When the leaking coil is identified, it is valved out.

For this analysis, the duration of a release due to a cooling coil failure is assumed to be four hours, based on the information in the Attachment 3. Such a very large waste release would be quickly identified by a rapid loss of water from the surge tank and an alarm from the liquid-level indicator on the surge tank. Then, waste would flow into the depressurized cooling water system, and the area radiation monitor (VAMP) would sound. The failed coil would be readily identified (because of its high radiation level) by Health Protection Department personnel using portable monitoring equipment.

The time for response to a cooling coil failure is such an important parameter in this analysis, that an engineered solution should be provided or the time should be made an operational safety Requirement (OSR). That is, a broken cooling coil should be rapidly isolated from the cooling water system.

\section{Frequency of Concurrent Failures}

In this analysis, cooling coil failures (or leaks) and cooling water header failures are treated as separate events with separate initiators. While these events could be concurrent, they do not occur simultaneously from a common initiator, such as an earthquake. As concluded in Reference 3 by Yau, an earthquake is not considered a credible initiator for a cooling coil failure.

However, it is believed that an earthquake could cause a failure of the cooling water header. Consequently, the header failure frequency includes the earthquake frequency.

Concurrent failures are possible. The frequency (F) is a function of both of the failure frequencies $(\hat{F})$ and their durations (d). The duration is the time from the time of a failure until the release (or leak) is stopped by valving operations. It makes no difference which of the two events occurs first.

The frequency of two concurrent, but independent, events is given by (Ref. 4):

$$
\begin{aligned}
& F=f_{1} d_{1} f_{2}+f_{2} d_{2} f_{1} \text { or } \\
& F=f_{1} f_{2}\left(d_{1}+d_{2}\right)
\end{aligned}
$$

where subscript $1=$ header failure and subscript $2=$ coil leak/failure. 
Frequency of Concurrent Failures (Continued)

For this analysis, a choice had to be made among the five cooling water systems in the Tank Farms, as listed in the attached reference. The choice is H-West, serving three tanks $(35,36$, and 37$)$, vecause this system has the most header length (51\%) outside the zone where the storn waters are monitored and divertable, as explained below on page 7 .

For the coil failure and header failure (Case 1), the frequency is:

$\mathrm{F}=2 \mathrm{E}-05 / \mathrm{hr} \times 8.9 \mathrm{E}-04 /$ tank-year $\times 3$ tanks $\times(3 \mathrm{hr}+4 \mathrm{hr})$

$\mathrm{F}=4 \mathrm{E}-07 / \mathrm{Yr}$.

Note that an event is considered to be incredible at this frequency, according to Reference 5 . However, should the combined response times $\left(d_{1}+d_{2}\right)$ be more than 17.5 hours, the event in case 1 is credible by the same criterion.

For the coil leak and header failure (Case 2), the frequency is:

$F=2 \mathrm{E}-05 / \mathrm{hr} \times 0.12 /$ tank-year $\times 3$ tanks $\times(3 \mathrm{hr}+168 \mathrm{hr})$

$F=1 \mathrm{E}-03 / \mathrm{Yr}$.

For the very small coil leak and a large header failure, the value is $2 \mathrm{E}-05 / \mathrm{hr}$, or about one per six years.

Waste Release Rate

To determine the release rate of waste from a concurrent failure/leak of the cooling water header and the cooling coil, the size of the individual leaks must be considered.

The first consideration was the cooling water header. If the cooling water header were to have only a slight leak, the pressure would be maintained by the surge tank. As long as the surge tank contains wates: the pressure in the cooling water line will remain at a higher pressure than the waste tank and any leaking that occurs will merely be water into the waste tank. Thus, only leaks large enough to deplete the surge tank (before a response by the operating personnel.) will provide an opportunity for waste to leak from the waste tank into the cooling water header. Therefore, all the cases analyzed involved a large leak in the cooling water header.

Leaks in the cooling coil were divided into three categories. The largest of these is a large break in the cooling coil (cooling coil failure, Case 1). Although the largest leak experienced was much smaller, it was assumed for this analysis that the equivalent of a "guillotine break" would occur. Thus, the hole in the coil would be limited by the diameter of the pipe (2"). The consequences for this hypothetical case are not reported in this study since this scenario was determined to have an incredible frequency.

The next category is referred to here as a cooling coil leak (Case 2). The cooling coil leak was assumed to be of the same size as the largest leak that has been experienced in our operations. For this scenario, the flow will be limited by the size of the hole in the cooling coil (because 
WSRC-TR-91-562

\section{Waste Release Rate (Continued)}

it is much smaller than the diameter of the coil) and does not depend on the position in the coil. Attachment 3 from WMT indicates this leak would result in the loss of about 250 gallons per day from the cooling system into the waste tank. Once the header has depressurized, this translates (by Attachment 3 or Reference 6) into a 100 gallon per day leak of waste into the cooling system. This is the release rate of waste to the ground used in the calculations for a cooling coil leak.

The smallest leak category is one that is conservatively assumed to always exist, but is not detectable by operating personnel or equipment. This very small leak is assumed to leak at the detection limit. The memo in Attachment 4 indicates that the detection limit is a 60 galion per day loss of water into the tank from a pressurized system. This translates into a potential waste leais of about 30 gallons per day from the tank into an unpressurized system (Ref. 6). This 30 gallons per day is used as the release rate of waste to the ground for the very small leak scenario.

The calculations include a conservative total quantity of waste released. In this analysis, it was assumed that all the waste entering the cooling coil would be released to the ground at the point of the cooling header break without any dilution. This is conservative in two aspects. First, the header must contain some quantity of cooling water or the siphon could not be established. This water would serve to dilute the waste to some extent prior to its release.

The second conservatism deals with holdup in the header. Unless something happens to break the siphon, once the valves are closed the flow will stop and some fraction of the waste in the header at that instant will remain in the header and not be released to the ground. Thus, assuming that all inaterial released from the coil reaches the ground is conservative.

The release rates listed above are multiplied by the length of the release to obtain the total number of gallons released to the ground. This total number number of gallons to the ground then serves as the input to the to the model, described next, which calculates the release which reaches the Savannah River.

Fraction of the Release Reaching the River

The consequences of all three cases of a release of waste from a leaking cooling water header depend on the location of the leak. Some parts of the headers are in tank farm areas where surface runoff flows into storm sewers that lead to a monitoring and diversion system. This monitoring and diversion system can divert contaminated water to a Retention Basin instead of Four Mile creek.

The other parts of the cooling water headers are in areas where the storm sewers lead to Four Mile Creek with no provision for monitoring or diversion. $A$ listing of the tanks served by each cooling water system (and the amount of each system where leaks are not subject to monitoring and diversion) is given in a table in Attachment 3 . 
WSRC-TR-91-562

\section{Fraction of the Release Reaching the River (Continued)}

The empirical model developed (from previous Tank Farm incidents) and used in the SAR (Section 5.4.10) states that, with diversion, no more than $0.04 \%$ of a liquid release to the ground reaches Four Mile Creek, and no more than $10 \%$ of the amount reaching the creek would reach the Savannah River. Thus, a conservative estimate of the fraction of the release that reaches the river is no more than $4 \mathrm{E}-05(0.048 \times 108)$.

A 1967 release from Tank 9 to a storm sewer (also described in section 5.4.10 of the SAR) is used to construct an empirical model for those header leaks that are not subject to monitoring and diversion. In the Tank 9 incident, about 1500 to $2000 \mathrm{Ci}$ of waste were released. Monitoring data from the creek eventually showed about $0.9 \mathrm{Ci}$ passed the last monitored point, the intersection of Road A (SC Route 125) and Four Mile creek. While it is believed that the release remained undetectable in the river, it is assumed for the purposes of this model that the $0.9 \mathrm{Ci}$ reached the river. Thus, the fraction reaching the river is conservatively estimated as no more than $0.9 / 1500$, or $6 \mathrm{E}-04$.

For this analysis, a choice had to be made among the five cooling water systems in the Tank Farms, as listed in the attached reference. The choice is H-West, serving three tanks (35, 36, and 37), because this system has the most header length outside the monitored zone (51\%). Thus, the fraction reaching the river is $6 \mathrm{E}-04$ in $51 \%$ of the releases from the header and $4 \mathrm{E}-05$ in $49 \%$ of the releases.

\section{Dose Consequences}

The consequences of the releases were calculated with the LADTAP computer program (Ref. 7) assuming the waste is High Heat Supernate (HHS) as detailed in the SAR (Ref. 1) in Table 4-7. HHS contains about 9.6 Ci of Cs-137/gallon.

The dose consequences to the maximum offsite individual are $1.8 \mathrm{E}-05$ Rem for Case 2 and 5.5E-06 Rem for Case 3, assuming the 3-hour header isolation time. Additional calculations for a 24-hour header isolation time, the approximate time in the incident of september 12, gave 1.5E-04 Rem for Case 2 and 4.4E-05 Rem for Case 3.

With the present 3-hour isolation time for a cooling water header leak, Case 1 is not a credible accident (i.e. its frequency is less than $1 \mathrm{E}-06 / \mathrm{Yr})$. Therefore, its consequences are not reported here. 


\section{REFERENCES}

1. B. M. Legler, et al, Safety Analysis-200 Area Savannah River Plant, Separations Area Operations, Liquid Radioactive waste Handling Facilities, DPSTSA-200-10, SUP-18, August 1988.

2. W. S. Durant, et al, 200-Area Fault Tree Data Bank - 1990 status Report (U), wSRC-TR-91-169, April 1991.

3. W. W. F. Yau, Seismic Resistances of the Cooling Coils for Type II and III Waste Tanks (U), WSRC-RP-91-937, september 1991 .

4. W. E. Vesely, et al, Fault Tree Handbook, NUREG-0492 (p XI16), January 1981.

5. J. C. Elder, et al, A Guide to Radiological Accident Considerations for siting and Design of DOE Nonreactor Nuclear Facilities, LA-1.0294, January 1986.

6. L. 0. Dworjanyn, Waste Tank Cooling Coil Leakage Calculations (U), WSRC-RP-91-1253, December 20, 1991.

7. J. C. Huang, Technical Manual, Environmental Risk Assessment, DPSTM-86-700-1, April 1986. 
WSRC-TR-91-562

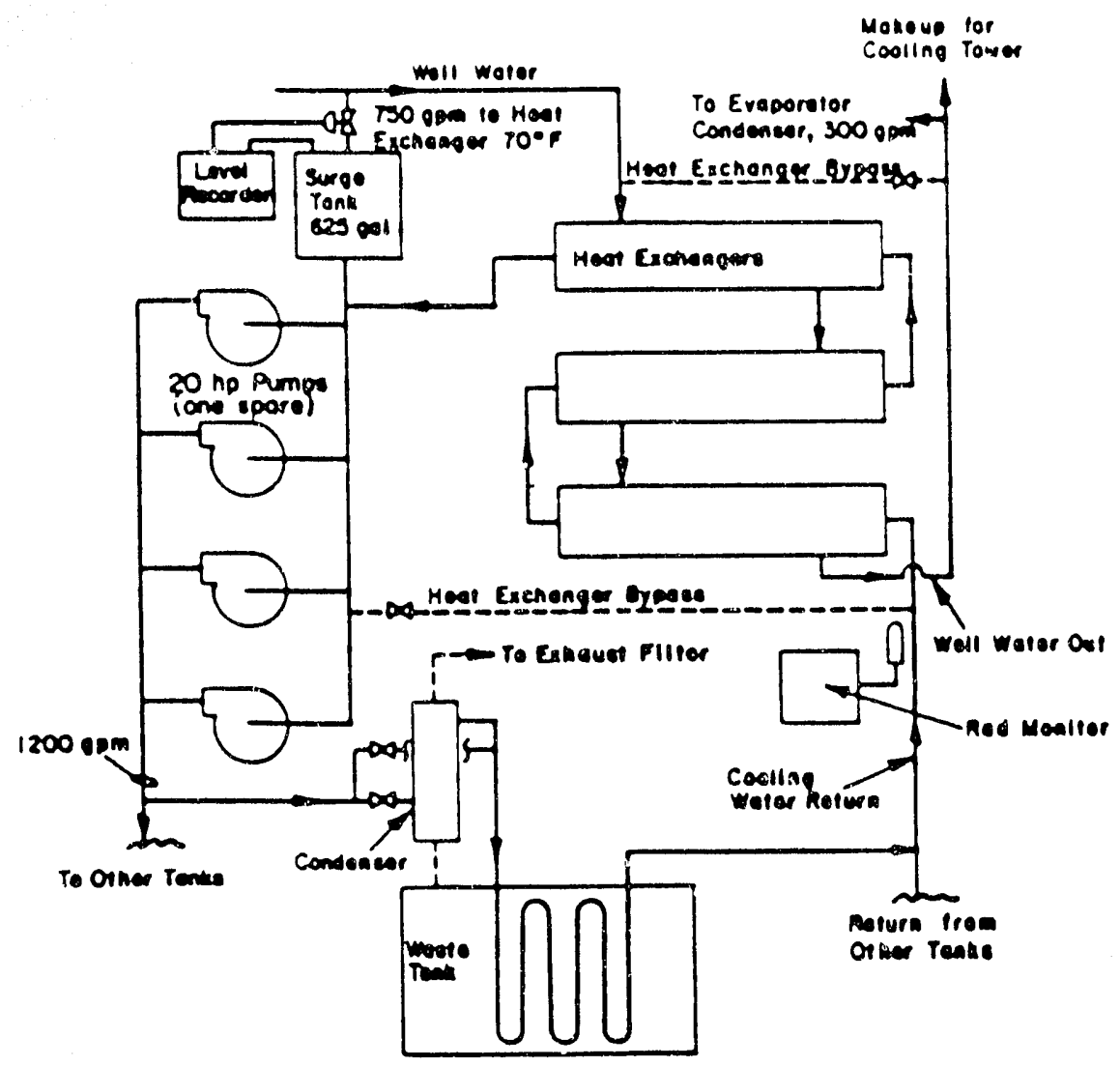

Figure 1. Waste Tank Cooling Water System 


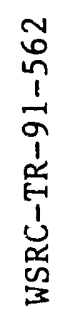
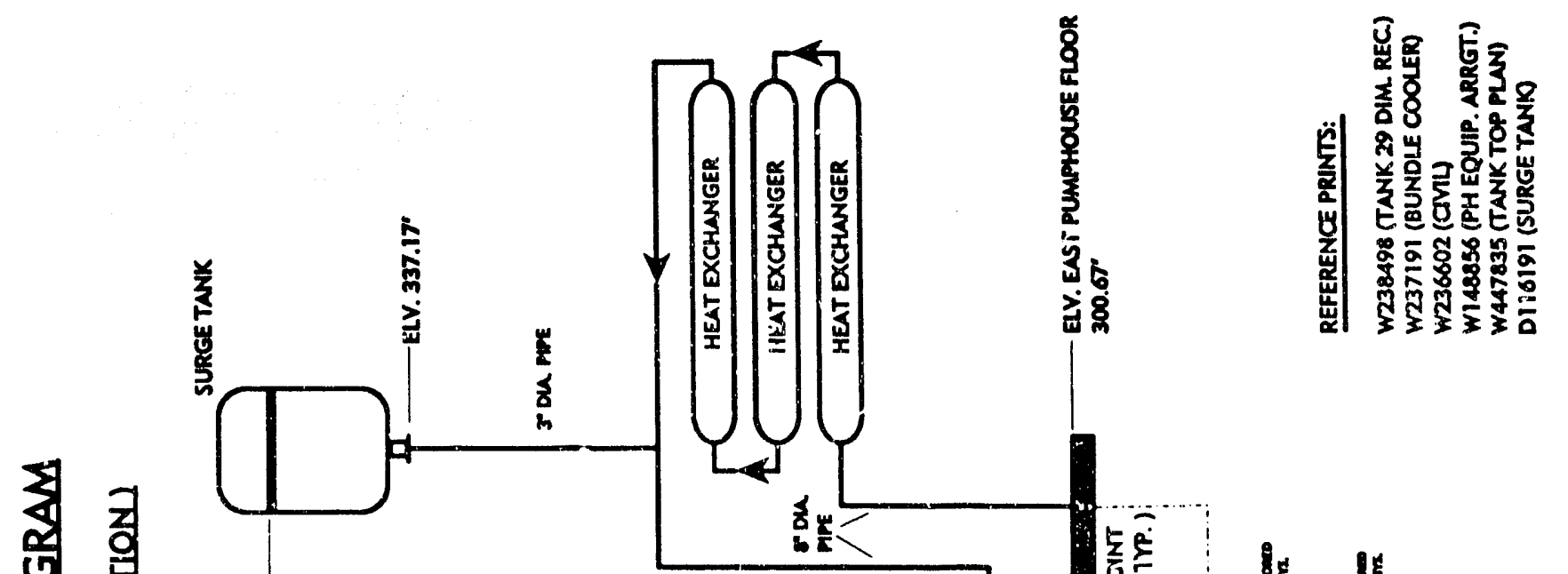

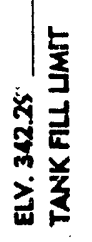

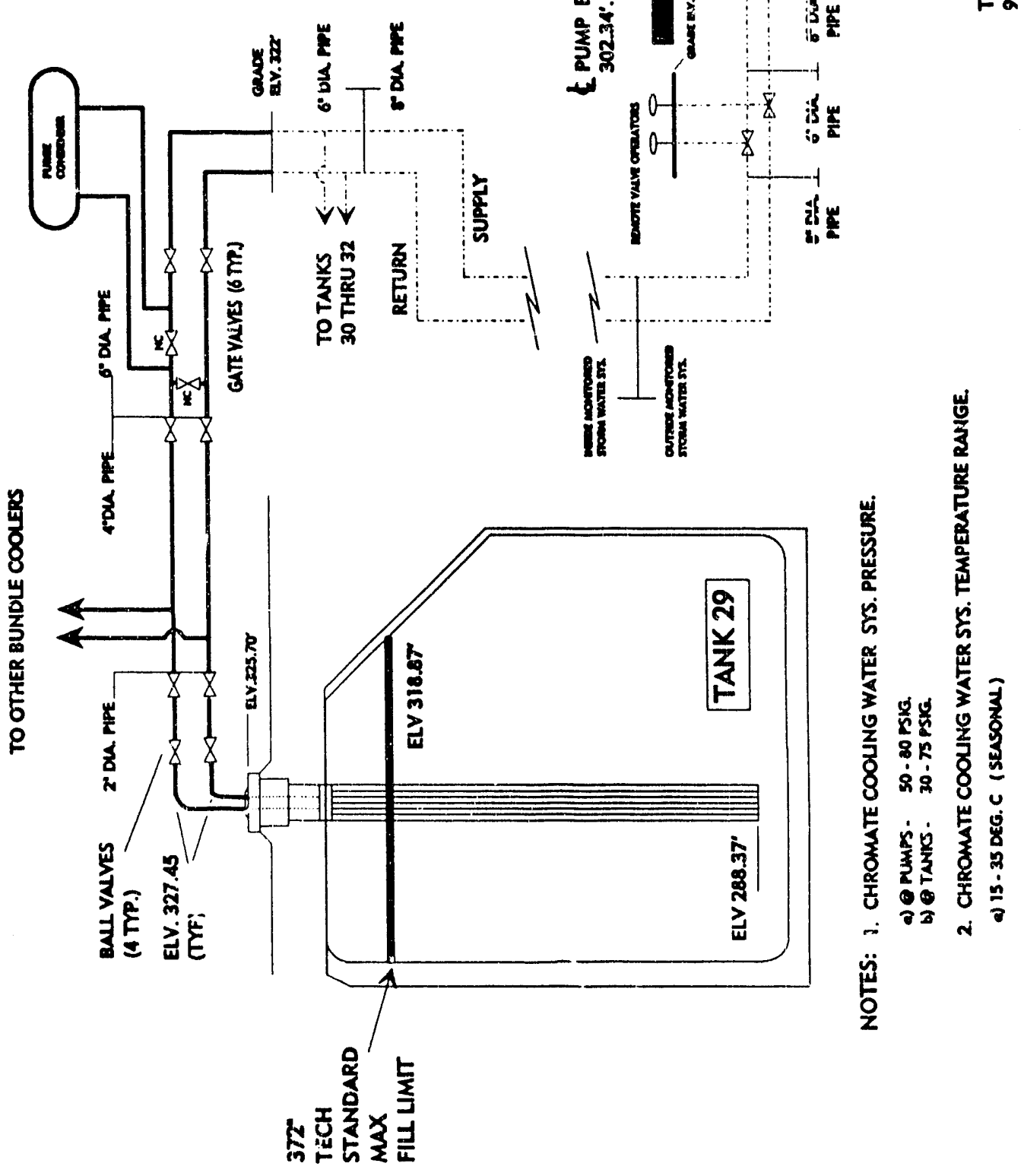

1
7
1
0
0
0
01 


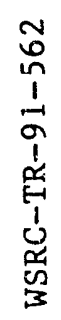

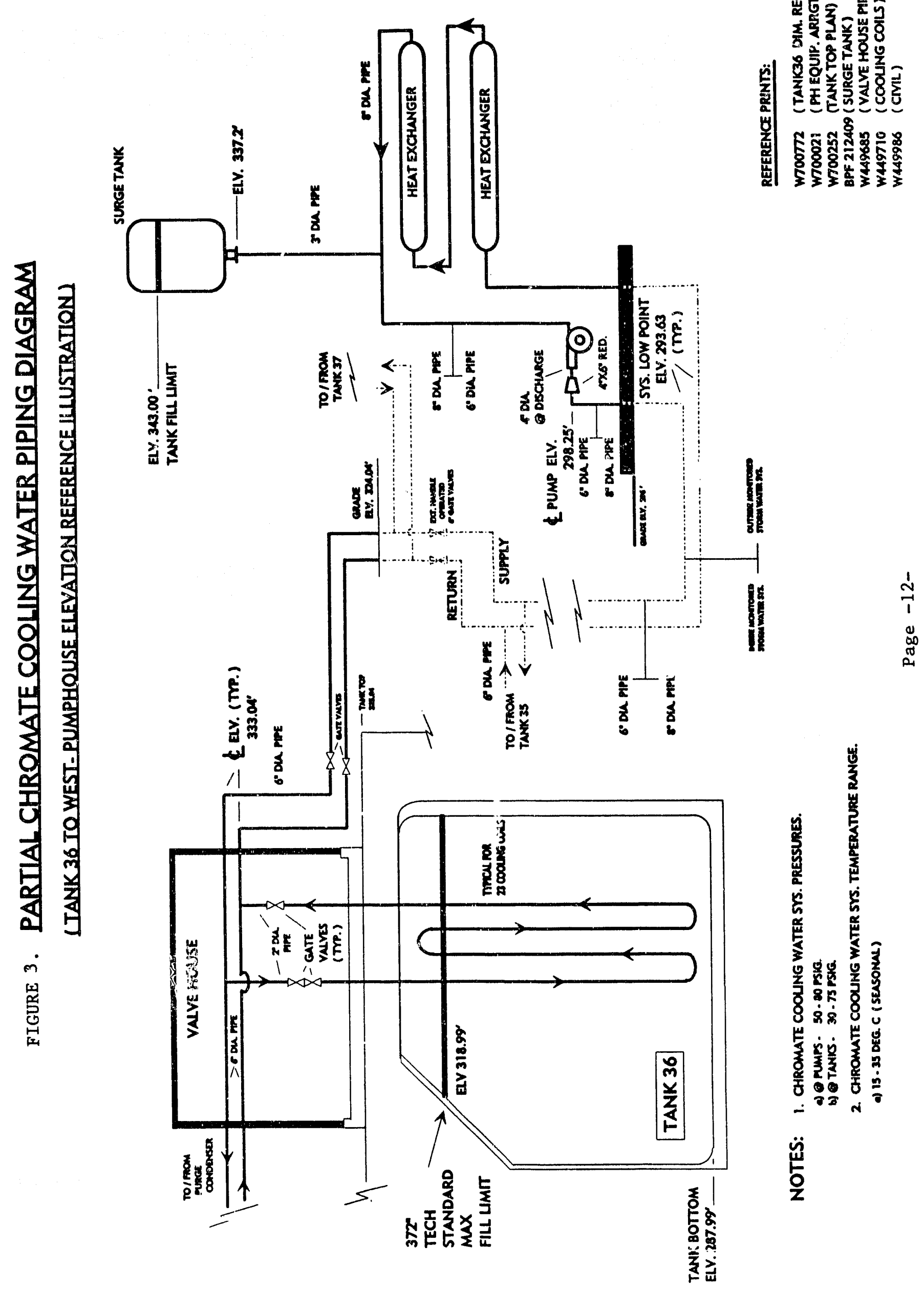




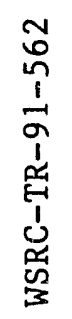

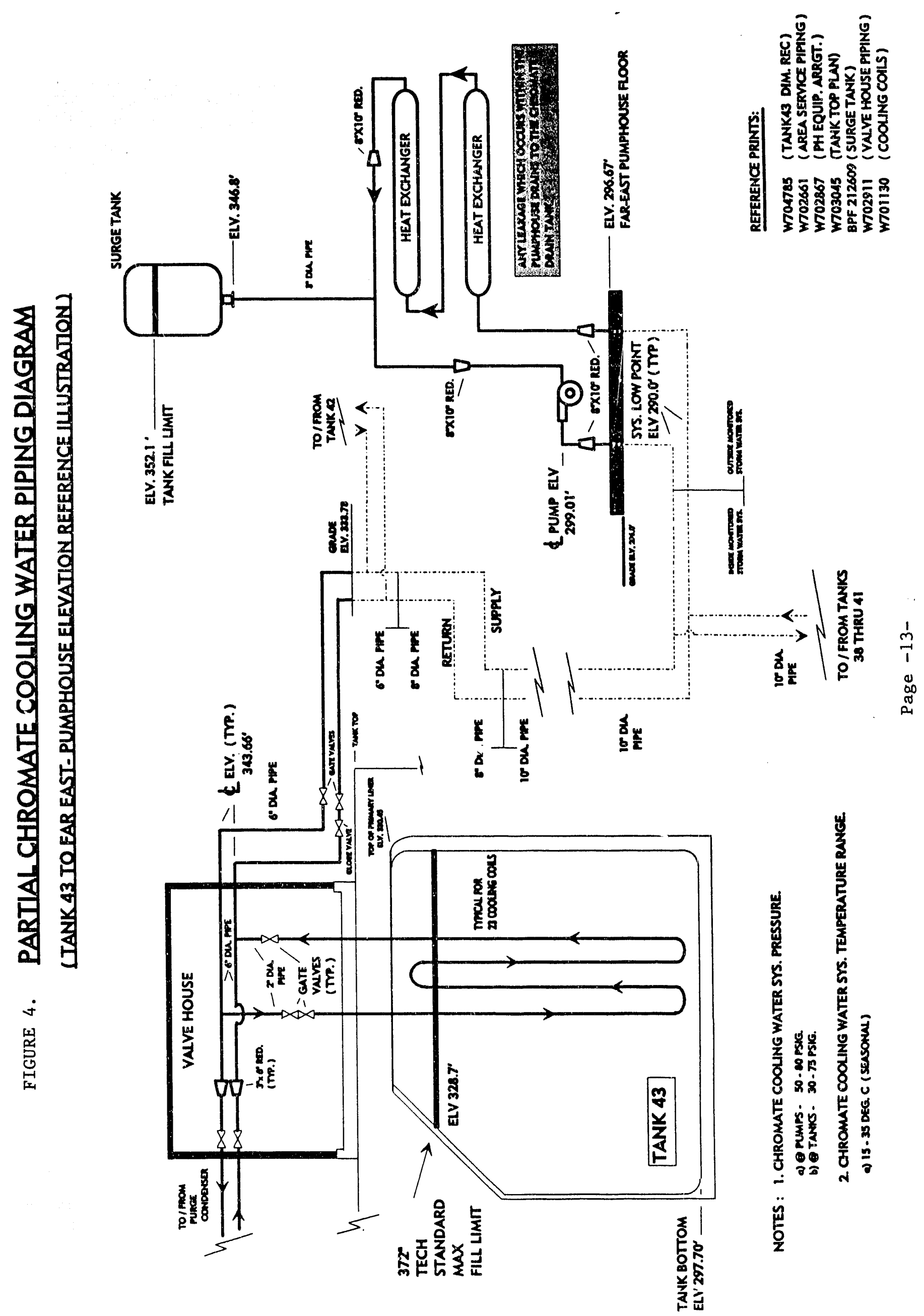




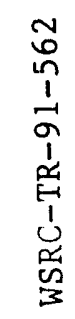

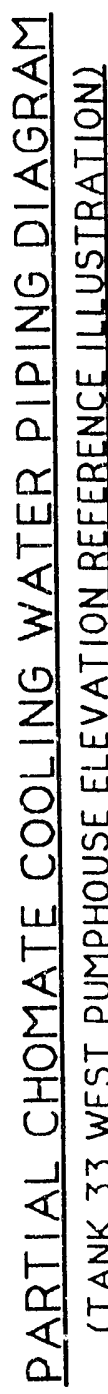

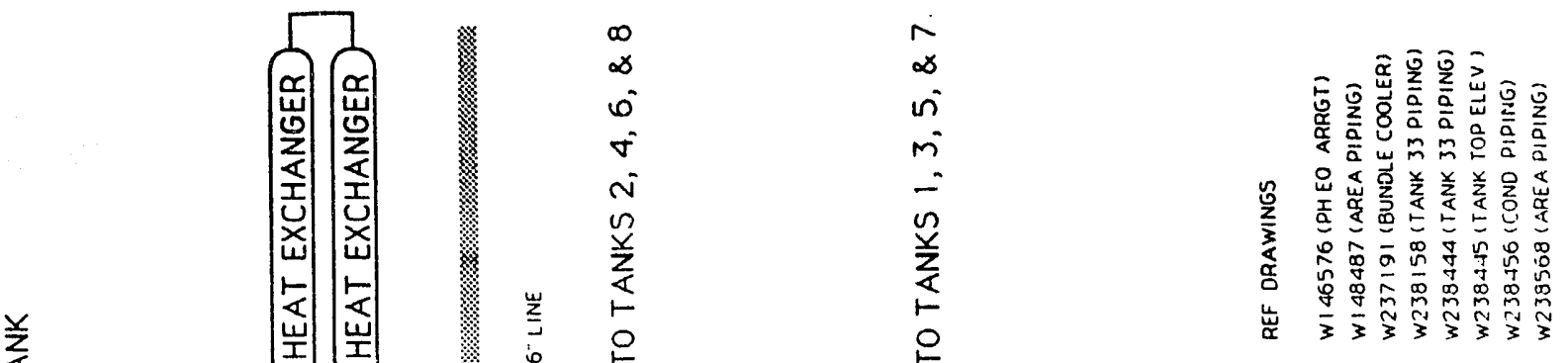

岁

号

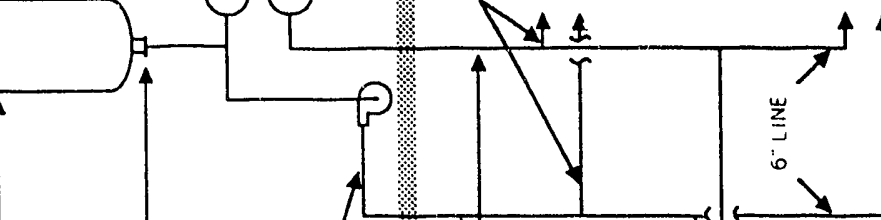

ָำ

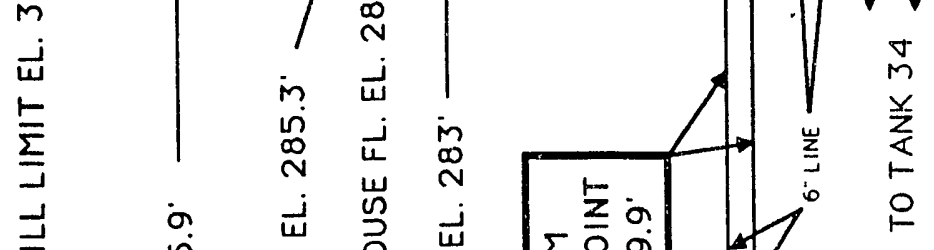

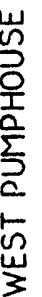

$---\frac{\frac{1}{1}}{1}$

in

品
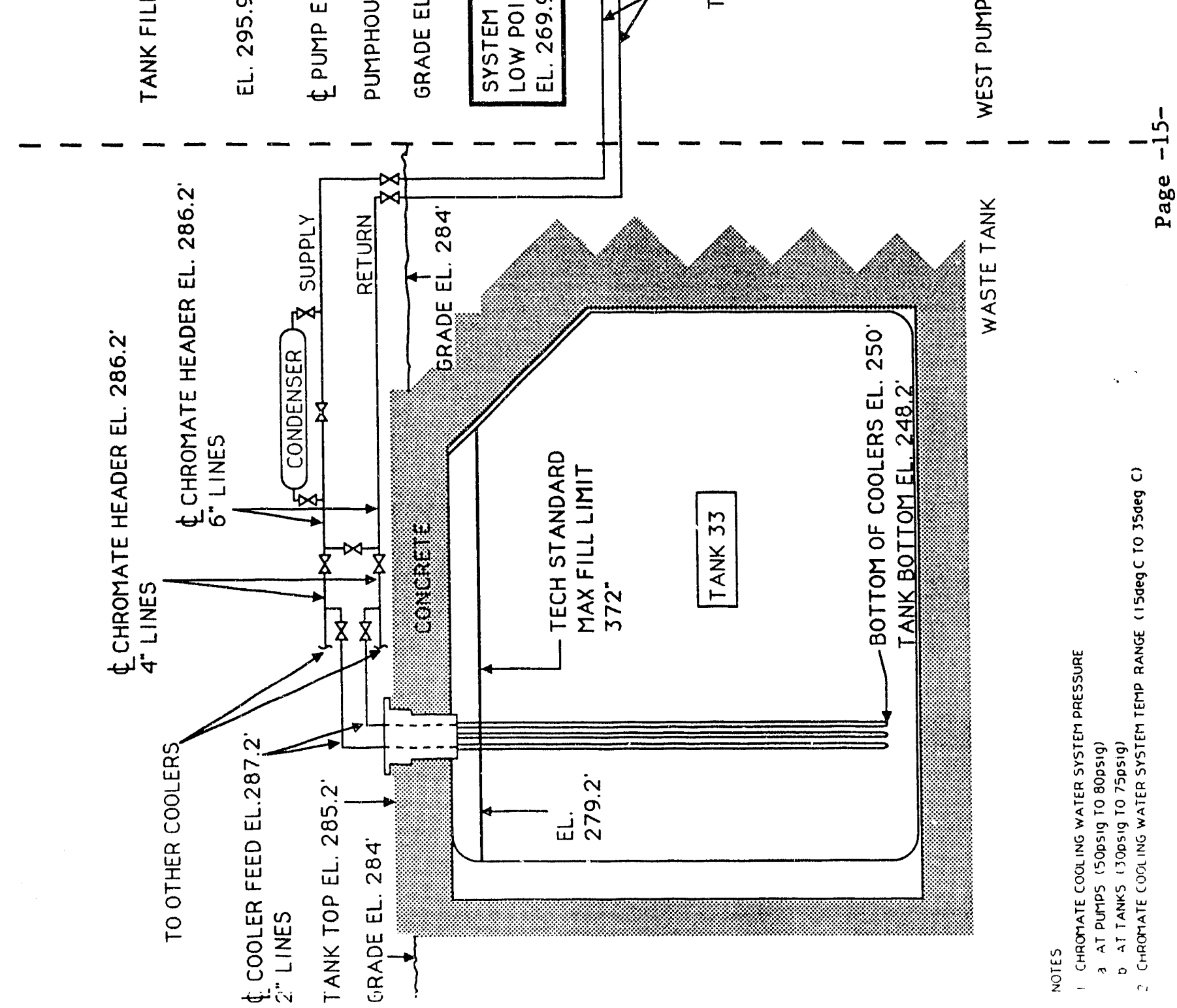
WSRC-TR-91-562

\section{ATTACHMENT 1}

\section{Contents}

Occurrence Report (Draft)

Root Cause Coding

Diagram: East Pumphouse Chromated Cooling Water System

Root Cause Analysis Chart
Number of Pages

4

6

1

6 


\section{Occurrence Report \\ Savannah River Site, Westinghouse Savannah River Company}

Pago 1 of 4

\begin{tabular}{|c|c|c|c|}
\hline \multirow[b]{2}{*}{ Name } & \multicolumn{3}{|c|}{$\frac{\text { Nuclear Materials Processing Division }}{\text { (Name of Facility) }}$} \\
\hline & $\frac{\text { Robert Wilson }}{\text { (Facility Manager }}$ & Title: & $\frac{803.557 .8592}{\text { 1010No. }}$ \\
\hline Name & $\frac{\text { Todd Grzech }}{\text { (Originator) }}$ & Title: & $\frac{803.557 .8233}{\text { V10No. }}$ \\
\hline
\end{tabular}

1. Occurrence Report No.

SRS-HTANK-91-64

2. Status and Report Dato

Date

[] Notification Report

M 10-Day Report

[] Final Pepont

4. DIVISION AN JRONECT: NMPD-MM

5. Facility, System, Building or Equipment:

6. Plantitiog

$200 \mathrm{H}$. Area

7. Oocurrence Discovered:

Date: $9 / 12 / 91$ Time:

5:45 p.m.

3. Oocurrenco Category (chock one)

Q/12/91

[] Emergency

a. Unusual Occurrence

(] Off-Normal

8. Occurrence Categorizod:

H Task Farm East Pumphouse Chromato Wator Lines

9. Notification of DOE Program Manager:
Name:
N/A
Date:
Time:

10 Notifications (Other):

WM DOE Represerifative

Carrol MeFall

Day Suporvision

Robert Wilson

Date: $9 / 12 / 91$

DOE HS\&E Representative

[]DP []NE []ER [X] EM

Date: 9/12/91 Timo: 6:30 p.m.

\begin{tabular}{|ccc|}
\hline Robert Wilson & Date: $9 / 12 / 91$ \\
\hline AEC & Time: $6: 45$ p.m. \\
& C. Travis & Date: $9 / 12 / 91$ \\
& Time: $7: 39$ p.m. &
\end{tabular}

\begin{tabular}{|c|c|c|c|}
\hline & Hal Morris (EPC) & Time: & \\
\hline \multirow[t]{2}{*}{ TSC } & & Date: & $9 / 12 / 91$ \\
\hline & Barbara Snyder & Time: & 7:41 p.m. \\
\hline \multirow[t]{2}{*}{ Other } & & Date: & $9 / 12 / 91$ \\
\hline & Carl Benjamin (HP) & Time: & 8:05 p.m. \\
\hline
\end{tabular}

11. Subject or Title of Occurrence

Chromate Water Loak at East Pumphouse ( $(v)$

\section{Description of Docurrence}

At 5:45 p.m. a low cooling water (CW; flow alarm for the East Pumphouse was received at the 242-1H Control Room. Upon investigation. it was discovered that all chromate cooling water pumps had lost prime and there was no cooling water flow to tanks 9-16 and 29-32. (see continuation page 4)

13. Operating Conditions of Facility at Time of Occurrence

Normal

14. Immediate Actions Taken and Results

Facility:

x] Operating

ai nis

Response to chromate water leak was inititated in accordance with Procedure 241-H-703.

DOES NOT CONTAN

UMCUASSIFIED CONTROUFi

NUCLEAR INFORMATION
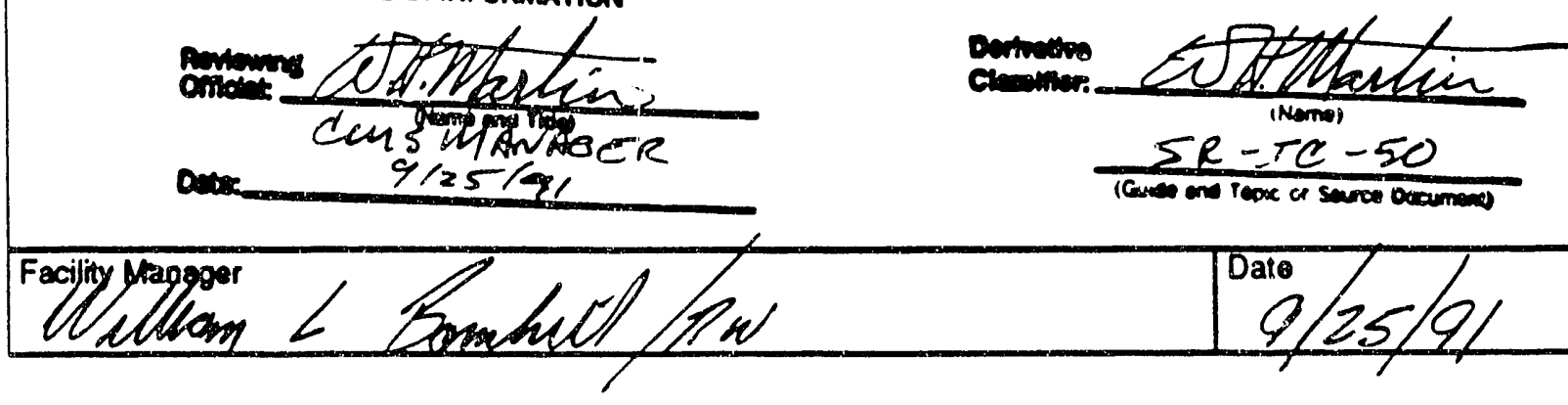


\title{
Savannah River Site, Westinghouse Savannah Biver Company \\ Occurrence Reporn No. \\ SRS.HTANK.91.64 \\ Date: $\quad$ 9!25:91 ${ }^{4}$
}

\begin{abstract}
15. Cause:
Direct Cause: (Mark only one)

Design Material

Personnel

$\square$ Procedure

Other

Explain:

Installation of large diesel fuel tank containment pad directly over chromate lines, thus imposing higher than design loads on ductile iron chromate cooling water lines.
\end{abstract}

Contributing Cause(s):
回 Design
Matorial
Personnel
Procedure
Other

Explain:

Use of ductile iron piping caused catastrophic failure of pipe due to load imposed stress.

Root Cause:

$\begin{array}{lll}\square \text { Procedure } & \square \text { Training } \\ \square \text { Dosign } & \square \quad \text { Material }\end{array}$

Explain:

Installation of a diesel fuel containment pad/dike over the cooling water header, without proper pipe protection, placed an undue stress on the cooling water lines which caused the pipe to fail.

16. Description of Cause:

A diesel fuel containment pad (weighing approximately 13 tons) was installed directly on top of the two chromate cooling water header lines that run to tanks 29-32. The two pipes were not properly protected prior to placing this concrete pad in place nor was the ground below the pad properly backfilled. Shifting of the chromate cooling water line due to normal use caused the concrete pad to impose a higher than design load on the line leading to its failure.

\section{Evaluation: (By Facility Managor)}

Inadequate design consideration prior to placing large load inducing objects over chromate cooling water lines without compensatory measures led to the eventual failure of this line.

As a result of the safety evaluation of this incident and a critical self-assessment, an Unresolved Safety Question (USO) was identified due to the possibility of radioactive wasie reaching the environment during a simultaneous failure of the cooling water header line and a lank cooling coil. This issue was resolved by a joint effort between W'M and SRL. The USO was assessed as being covered by the SAR process and USQ criteria were not exceeded. Safety Significance: "F"

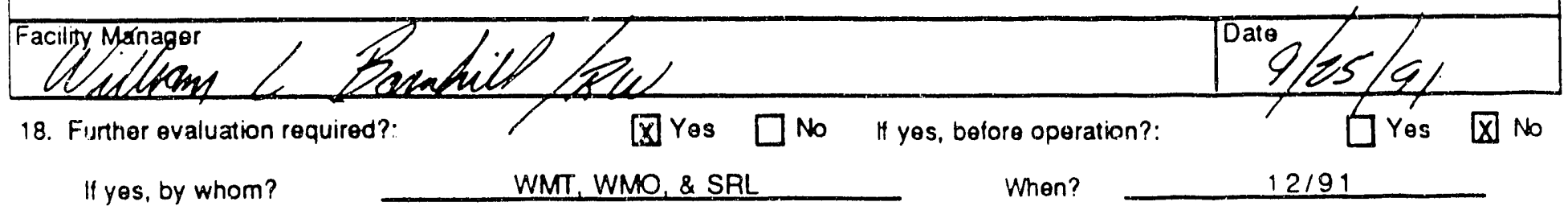




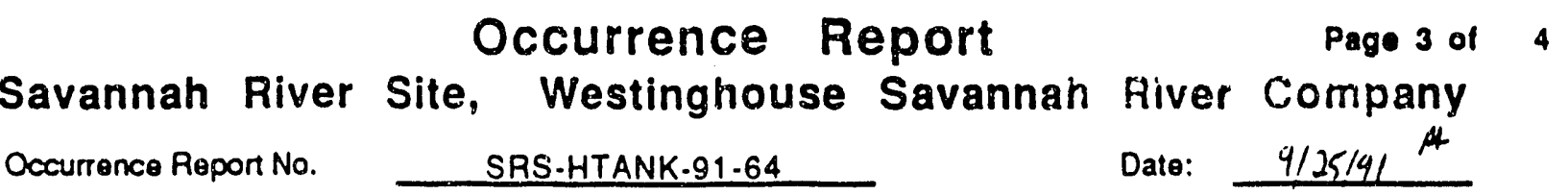

19. Corroctive Action:

Taken:

-The Chromate Cooling Water System for tanks 9-16 and 29-32 was valved out, excavation and repair of the line was completed, and the system was returned to service.

-A JCO was approved to allow for the use of all CW systems with the headers located in an unmonitored zone. - An Unresolved Safety Question (USQ) was determined reasonable by WMT, and the USQ process was initiated. - The assessment by SRL is that the USQ is within the existing SAR and none of the USQ criteria jerexceeded. - Environmental composite samples downstream of release were pulled and indicated below normal levels for chromium and radioactivity.

To be suppliod:

- As part of the JCO, all tank cooling coils will be pressure tested and blanked off if found to be leaking.

Furthermore, a continuing program to test all coils will be initiated each quarier. (WMO, 10/91).

-SRL will document USQ ovaluation in a report. (SAL. 10/91!

- Eveluate/relocate the 241.74H diasel generator fuel tank and containment dike from top of chromate cooling water lines. (WMP, 11/91)

(Continued on Page 4)

20. Impact on Envrionment, Salety, and Heatth:

NONE

21. Programmmatic impact:

NDNE

22. Impact on codes and standards:

NONE

23. Final evaluation and lessons loarned:

To be supplied in Final Report

24. Similar Occurrence Report numbers:

WM-IM-89-21

WM-1M-90-67

25 (A). WSRC Signatures:

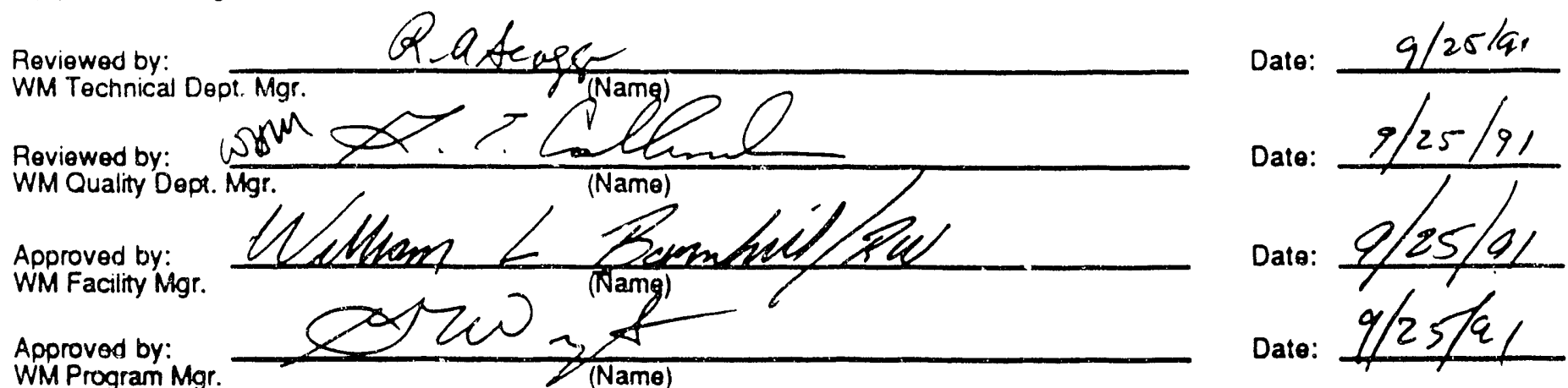


SRS.HTANK-91-64 (Continuation)

12. Procedure 241-H-703 was initiated in an attempt to repressurize the chromate cooling water system and determine the source of the leak (supply or return side). The surge tank, which is used to mairitain pressure on the system at all times (i.e., it is at an elevation higher than any waste tank), level kept decreasing while personnel were iroubleshooting the failure. Personnei at the Easi Pumphouse observed water bubbling up out of the ground approximately 75 yards west of the East Pumphouse. Management was notified and informed personnel to shut of the cooling water pumpe and valve out the surge tank to prevent any further chromate water from reaching the ground. The leak site was barricaded off, and sandbags and mop heads were used to try to prevent spreading of the chromate water. Due to the amount of leakage, some chromate water did find its way to a storm drain and enter the unmonitored stormwater system. Judging from the flow of water, it was deterinines that the leaksite was just north of 241-64H adjacent to a concrete sump pad that contained a diesel fuel tank. Excavation of this area in order to repair the lines was initiated.

19. To be supplied:

-Procedures $241-\mathrm{H}-703$ and $241-\mathrm{F} \cdot 703$ will be revised to prevent the migration of waste to the environment during a simultaneous leak of the cooling water header and a tank cooling coil. This will be done by having personnel valve out both the supply and return sides of the individual tank cooling water systems during signs of a main header failure. (WMO, 10/91)

-Investigate ine installation of siphon breaks on the tank cooling water systems. (WMO \& WMT. $11 / 911$ 
Unusual Occurence Report SRS-HTANK-91-64

Page 1 of 6

Sheryl A. Pucko, WMT SAPucto

January 21, 1992

ROOT CAUSE CODING

(per Root Cause Analysis Handbook WSRC-IM-91-3)

\section{Causal Factor \#1}

Installation details not adequately specified on prints

Root Cause \#1:

Equipment Difficulty
Construction/Fabrication
Design
Design Input/Output
Design Output LTA
Design Output Not Clear

The design prints for both projects in question contained unclear specifications.

Print W236602 (issued under Project 981232), used for the installation of the chromate cooling water lines, specifies the minimum cover over the chromate cooling water lines to be $2^{\prime} 6^{\prime \prime}$. The type of cover to use was not specified. "Cover" could imply earth, concrete, or any other type of backfill that is normally used. Also, a maximum load limit for the chromate cooling water lines was not given in W236602. It should be noted that there is a relationship between loading and earth cover (i.e., the concrete slab may not have exceeded the load limits of the piping if there had been more earth or backfill between the piping and the concrete.)

Print W727047 (issued under Project S-2081), used for the installation of the concrete diesel generator fuel tank pad, specified that the pad should extend a minimum of $1{ }^{\prime} 6$ " below grade level. A maximum depth was not specified; therefore, the concrete pad could have been poured to any depth without violating design print specifications.

Proposed Recommendations: (Actual action items to be included in final occurrence report)

1) Implement a comprehensive design and work control program to provide a more structured approach for the review and verification of proposed design activities. (WMO, WMT) - complete (see WM-QI-1031, WM-QI-1032, and WM-QI-1033)

2) Review other cooling water systems for locations of possible overloading (overstressing) of cooling water lines. (WMO) 
A comprehensive design control program did not exist at this time

Root Cause \#2

\author{
Equipment Difficulty \\ Equipment Reliability/Design \\ Installation/Corrective/Preventive \\ Maintenance Difficulty \\ Management Systems \\ Configuration Control \\ Designs/Documentation Not Complete
}

A comprehensive design control program such as exists today did not exist during the design and installation of both the chromate cooling water lines and the concrete diesel fuel tank pad. WM-QI-1031, WM-QI-1032, and WM-QI-1033 designate responsibiities and requirements for design control for Category I and Category II Projects and Division Managed Tasks performed by the Waste Managernent Program Management Team (WM-PMT). These procedures provide a much more organized approach for design control than was previously used. The reviews and verifications required per these procedures for implementing new designs or changes to designs are quite extensive. The specifications for each design would have been more complete, and the design prints for the chromate cooling water lines would have been reviewed during the clesign of the concrete pad.

Proposed Recommendations: (Actual action items to be included in final occurrence report)

See Recommendation \#1 for Root Cause \#1

Causal Factor \#3

A Site Clearance Permit for installing the fuel tank pad was not issued

Root Cause \#3

Support Difficulty
Other Organization
Procedures
Not Used
Training and Reference Procedure

At the time of the design and installation of the concrete diesel fuel tank pad, a site clearance permit was required for all new installations and excavation. However, site clearance was never requested for the insiallation of this concrete pad. If site 
clearance had been requested, the Site Configuration Control Group would have reviewed the design print for the concrete pad and compared it with existing site maps and would have identified any interferences at grade level and below (i.e., the underground chromate cooling water lines).

WSRC Engineering and Engineered Services Procedure Manual 1E, Procedure 3.02, approved $9 / 24 / 90$ is the current procedure which requires the Project Sponsor or individual installing a new facility or modifying an existing facility to prepare a Site Clearance Request Form which includes an interference check. The requestor must list the drawings that have been checked for interferences. The Site Configuration Control Group then checks the Site Development Maps for any interferences and identifies and includes these interferences on the Site Clearance Permit.

Proposed Recommendation: (Actual action items to be included in final occurrence report)

1) Incorporate site clearances into design and/or work control procedures (WMWE)

Causal Factor \#4

East Pumphouse surge tank level strip chart located at East Pumphouse (not in control room)

Root Cause \#4

\author{
Equipment Difficulty \\ Equipment Reliability/Design \\ Design \\ Design Input/Output \\ Design Output LTA \\ Design Output Not Correct
}

The East Pumphouse surge tank level strip chart is located at the East Pumphouse, and not in the control room. Therefore, the operators were not aware that the surge tank level was decreasing until the chromate cooling water low pressure alarm was received in the control room. By the time this alarm was received, the surge tank had completely emptied. Although the rate of decrease of the surge tank is not exactly known, it is possible that if the strip chart had been locaied in the control room, the operators would have noticed a downward trend in the surge tank level before the chromate cooling water low pressure alarm was received. An investigation to determine the cause of the surge tank level decrease could have been initiated sooner, thus mitigating the chromate release to the environment. 
Propesed Recommendations: (Actual action items to be included in final occurrence report)

1) Relocate the East Pumphouse surge tank level strip chart to the $1 \mathrm{H}$ control room. (WMO)

2) Modify the operator runbooks to require the operators to take surge tank level readings more frequently (every one or two hours). (WMO,WMT)

\title{
Causal Factor \#5
}

Procedure $241-\mathrm{H}-703$ requires operators to locate leaksite without recognizing possibility for potential environmental release

Root Cause \#5

\author{
Operations Difficulty \\ Producton Organization \\ Procedures \\ Wrong/Incomplete \\ Facts Wrong/Requirements Not Correct
}

Procedure 241- $\mathrm{H}-703$ covers the actions to be taken when there is a rapid decrease in a surge tank level. Per this procedure, the leaking cooling water header must first be identified and isolated. After this is accomplished, it is required per this procedure to "keep a close watch on the surge tank level, keeping it as near full as possible in order to keep as much head pressure on the coils as possible." However, during attempts to repressurize the cooling system, more chromate cooling water was released to the environment. The leaksite was believed at that time to be on the supply header to tanks 29-32 while it was actually on the return header. Had attempts to repressurize the system not been made, the release to the environment would have been mitigated.

Proposed Recommendation: (Actual action items to be included in final occurrence report)

1) Modify Procedure 241-H-703 so that WMT and WMO Managers' approvals are required before attempts to repressurize the cooling water system are initiated. (WMO, WMT) 
Page 5 of 6

Causal Factor \#6

Adequate spill containment materials not readily available

Root Cause \#6

Operations Difficulty
Production Organization
Procedures
Wrong/Incomplete
Facts Wrong/Requirements Not Correct

Situations arise where spills must be isolated before the Spill Response Team is able to reach the spill location. During this incident, the operators isolated the drainage ditch from the leaksite with sandbags and mop heads. Attempts to pressurize the system caused chromate water to bubble up out of the ground and flow over the sandbags and mop heads and into the drain. More absorbant and less porous materials could have been used instead of, or in conjunction with, the sandbags and mopheads. This would have mitigated the release to the unmonitored outfall.

Proposed Recommendation: (Actual action items to be included in final occurrence report)

1) Implement a program to store more adequate spill control materiais in each pumphouse, and in other locations as appropriate (WMO)

\title{
Causal Factor \#7
}

East Pumpinouse area is outside radiation monitored stormwater zones

Root Cause \#7

\author{
Equipment Difficulty \\ Equipmerit Reliability/Design \\ Design \\ Design Review/Verification \\ Incomplete Review/Verification
}

The East Pumphouse in H-Area supplies chromated cooling water to Tanks 9-16 and 29-32 (see attached sketch). A portion of the piping in this cooling system lies outside radiation monitored stormwater zones. If the leak had occurred in a radiation monitored stormwater zone, the zone could have been manually diverted (or automatically diverted if the chromate cooling water activity was detected) to a retention basin. This would have mitigated, if not prevented, the release to the outfall. 
Proposed Becommendations: (Actual action items to be included in firlal occurrence report)

1) Develop a plan for improving safe disposition of stormwater run-off around all pumphouses (WMO, WMT, WMWE)

Modifications to be considered include:

a) Connect the existing unmonitored stormwater ditch to an existing monitored stormwater system

b) Install a manhole which includes radiation detection (similar to existing design)

c) Regrade area around the cooling water header that is outside a monitored zone so that in the event of a leak, chromated water would drain into the existing monitored stormwater ditch (WMO)

Item of Note \#1

Procedure does not specify placement of personnel near suspected leaksite

Root Cause \#1 Operations Difficulty

Production Organization

Procedures

Wrong/Incomplete

Facts Wrong/Requirements Not Correct

Procedure 241-H-703 does not require a person to be monitoring a suspected leaksite for sudden increases in leakage, while attempts are being made to repressurize the cooling water system. Although in this instance a WMWE supervisor was watching the suspected leaksite, and saw the cooling water start pouring out and running over the sandbags and into the urain, the procedure did not require someone to be watching the suspected leaksite. If the WMWE supervisor had not been standing there, the cooling water release to the environment could have been increased.

Proposed Recemmendation: (Actual action items to be included in final occurrence report)

1) Modify Procedure $241-\mathrm{H}-703$ so as to require personnel to be watching the suspected leaksite for a sudden increase in the rate of flow of release, while attempts to repressurize the cooling system are being made. (WMO. WMT) 
है

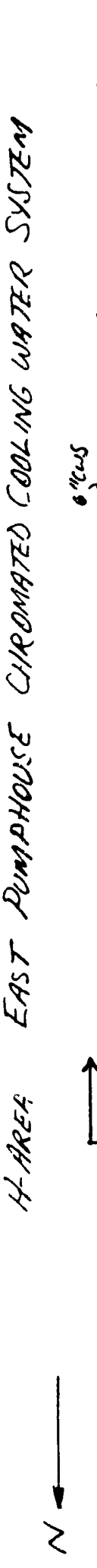

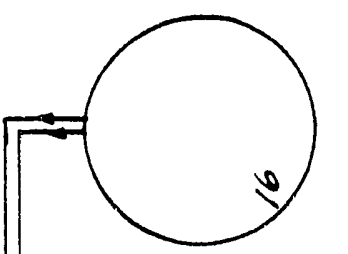
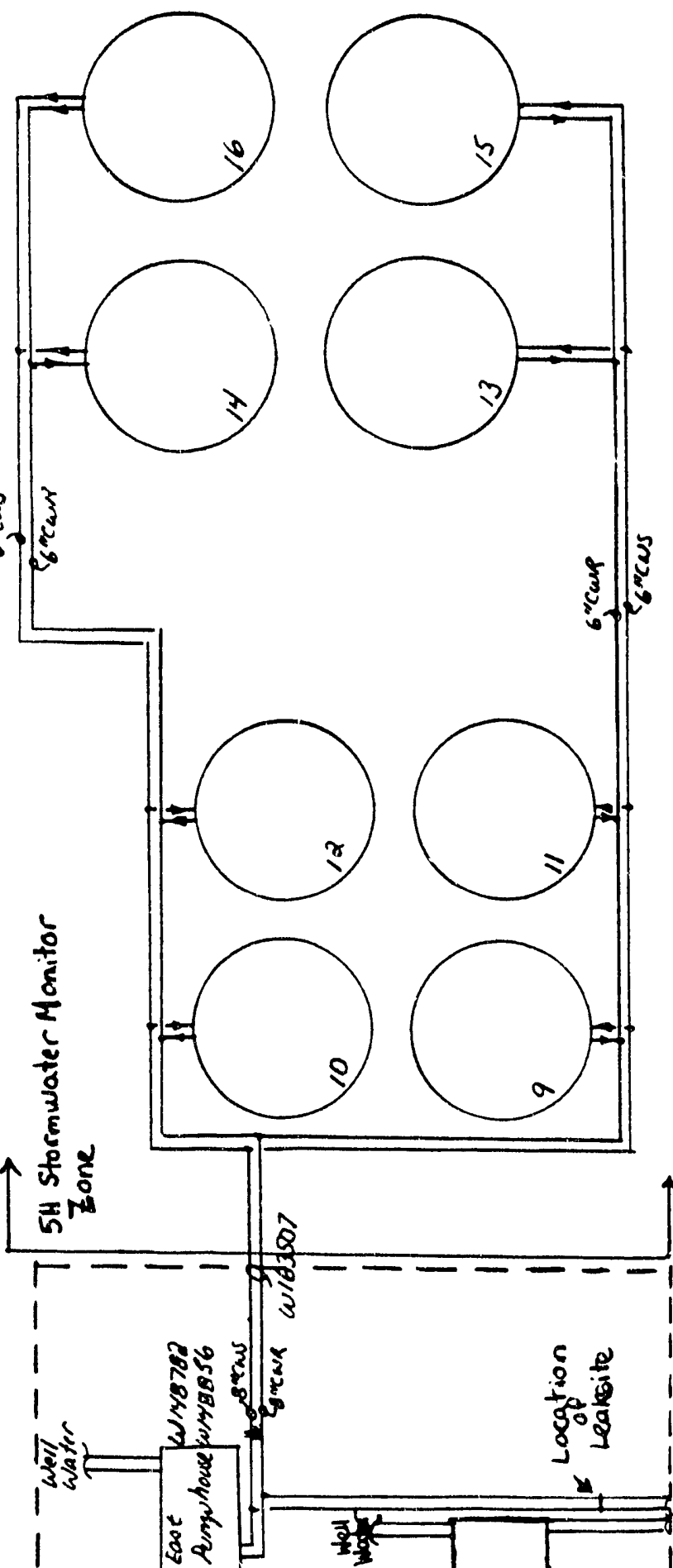

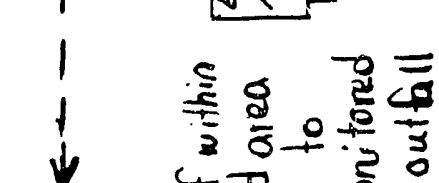

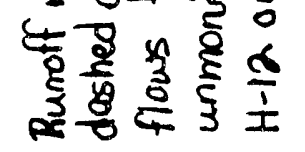
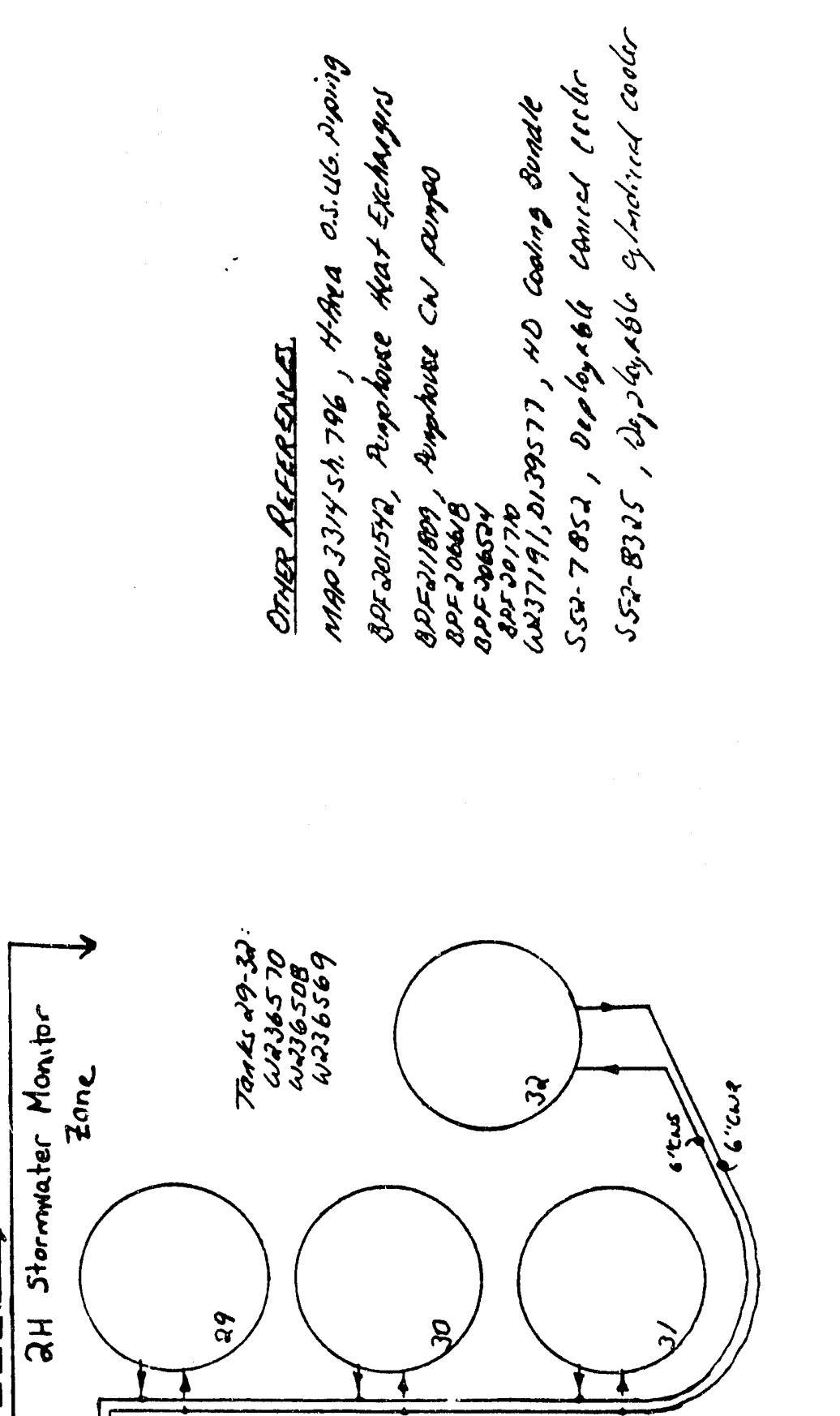

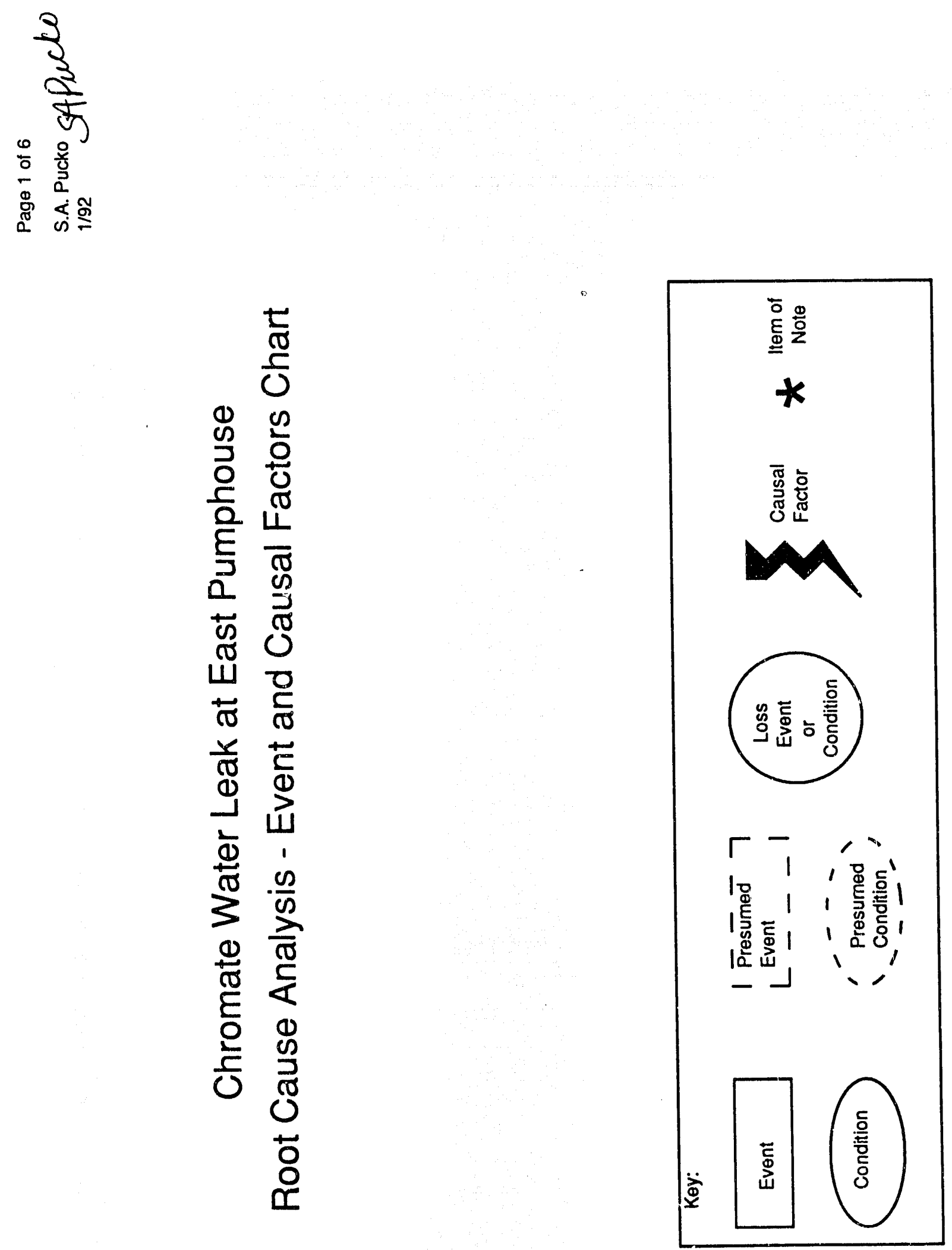
高

(I)

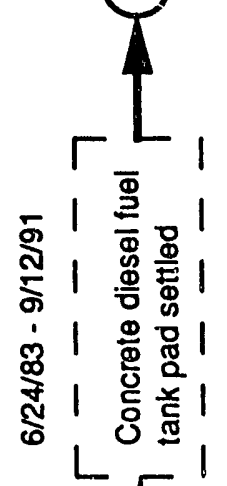

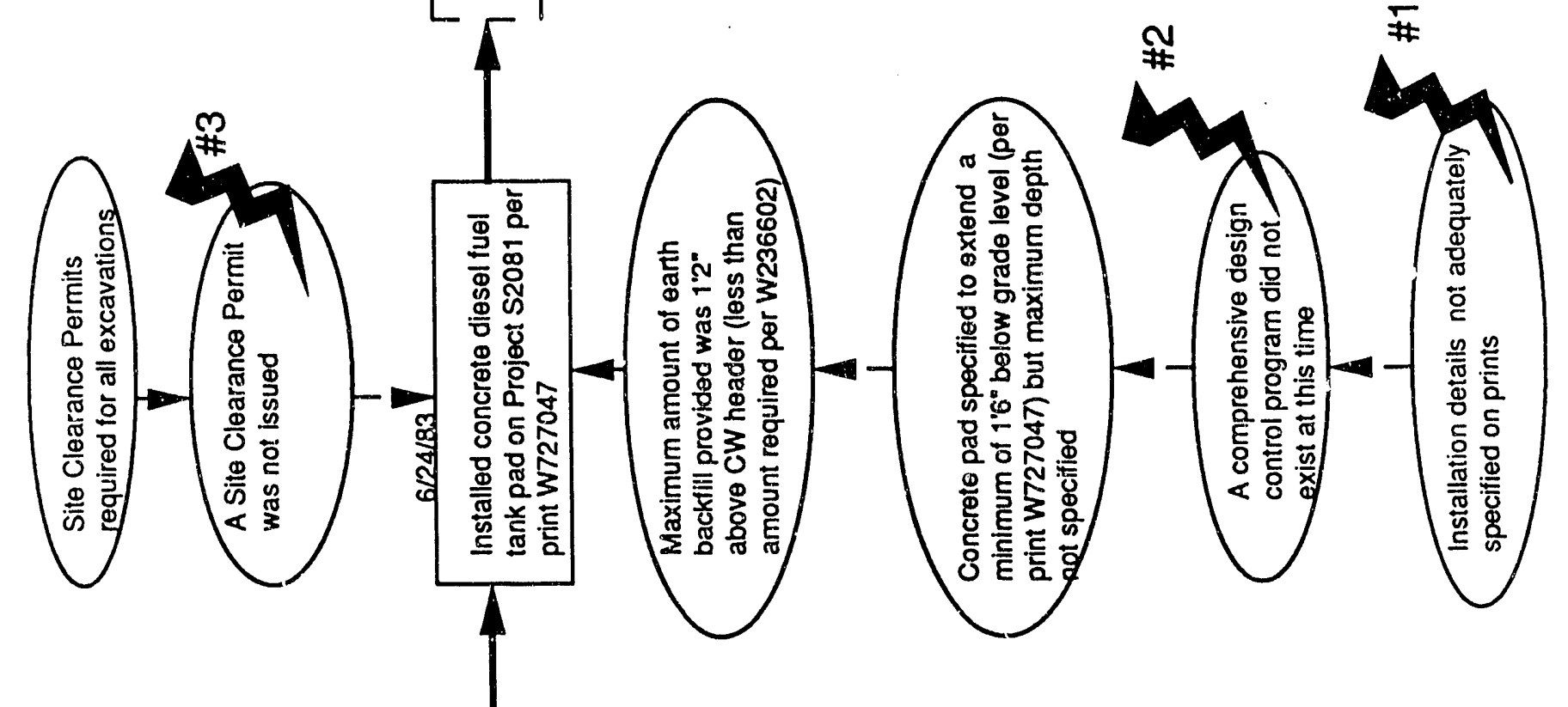

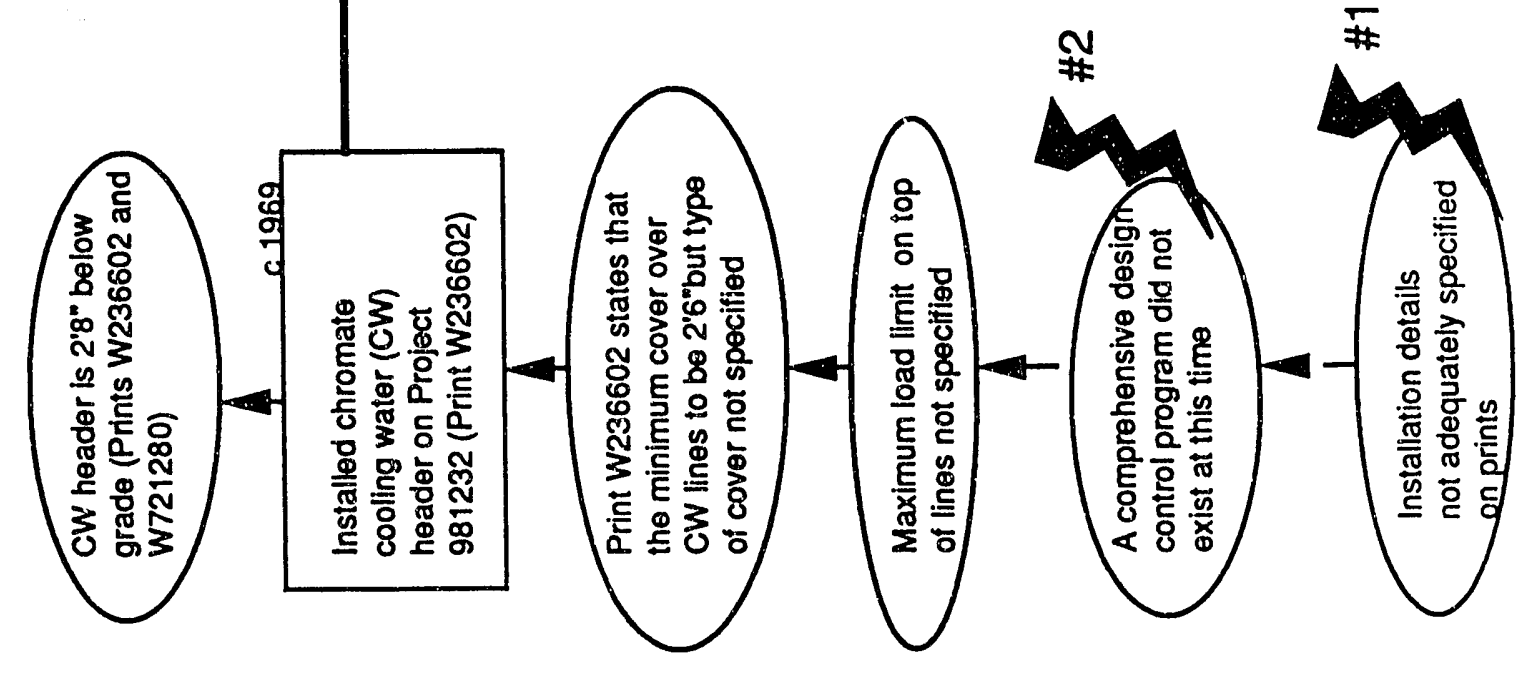




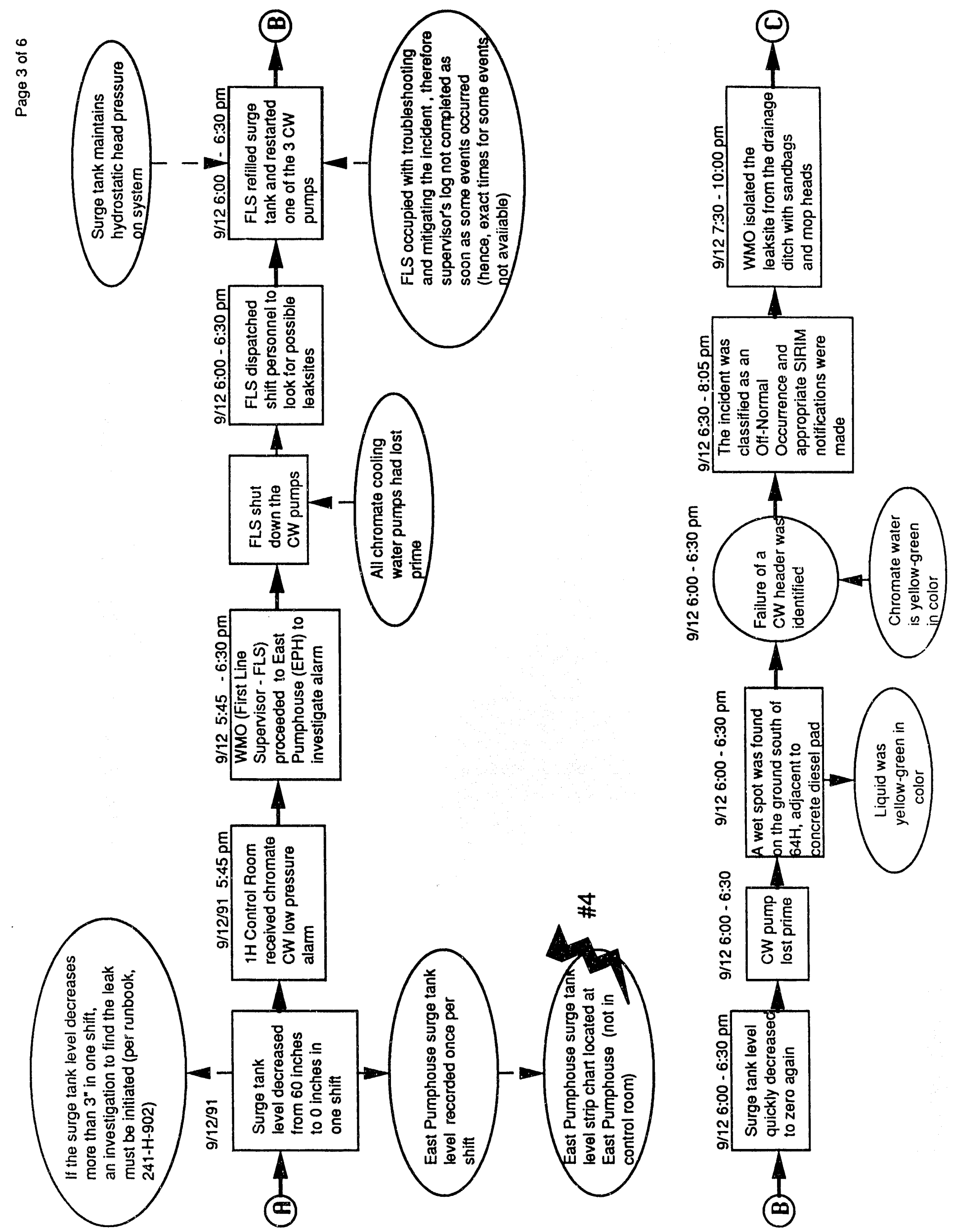




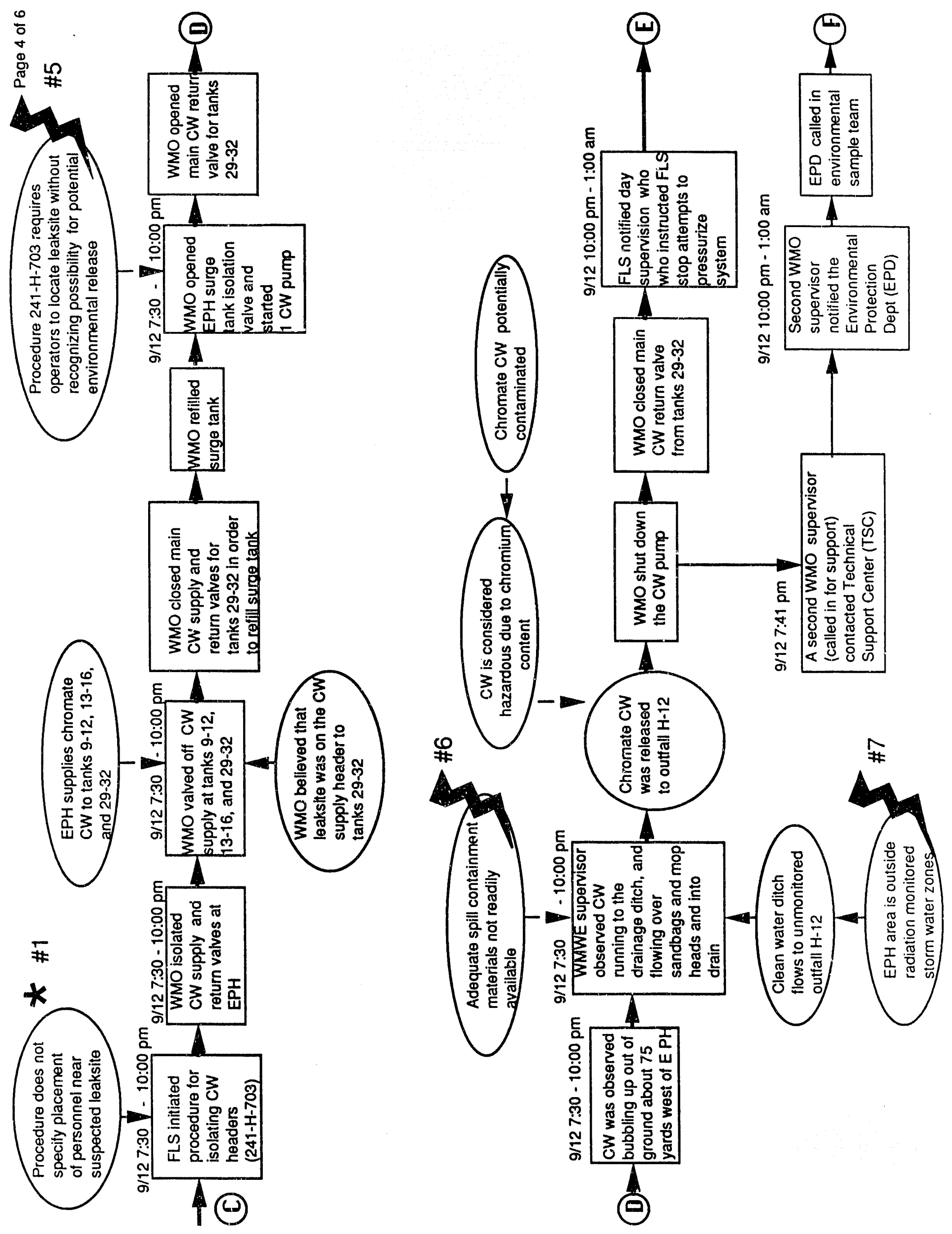


0
0
$i$
0
8
8
0
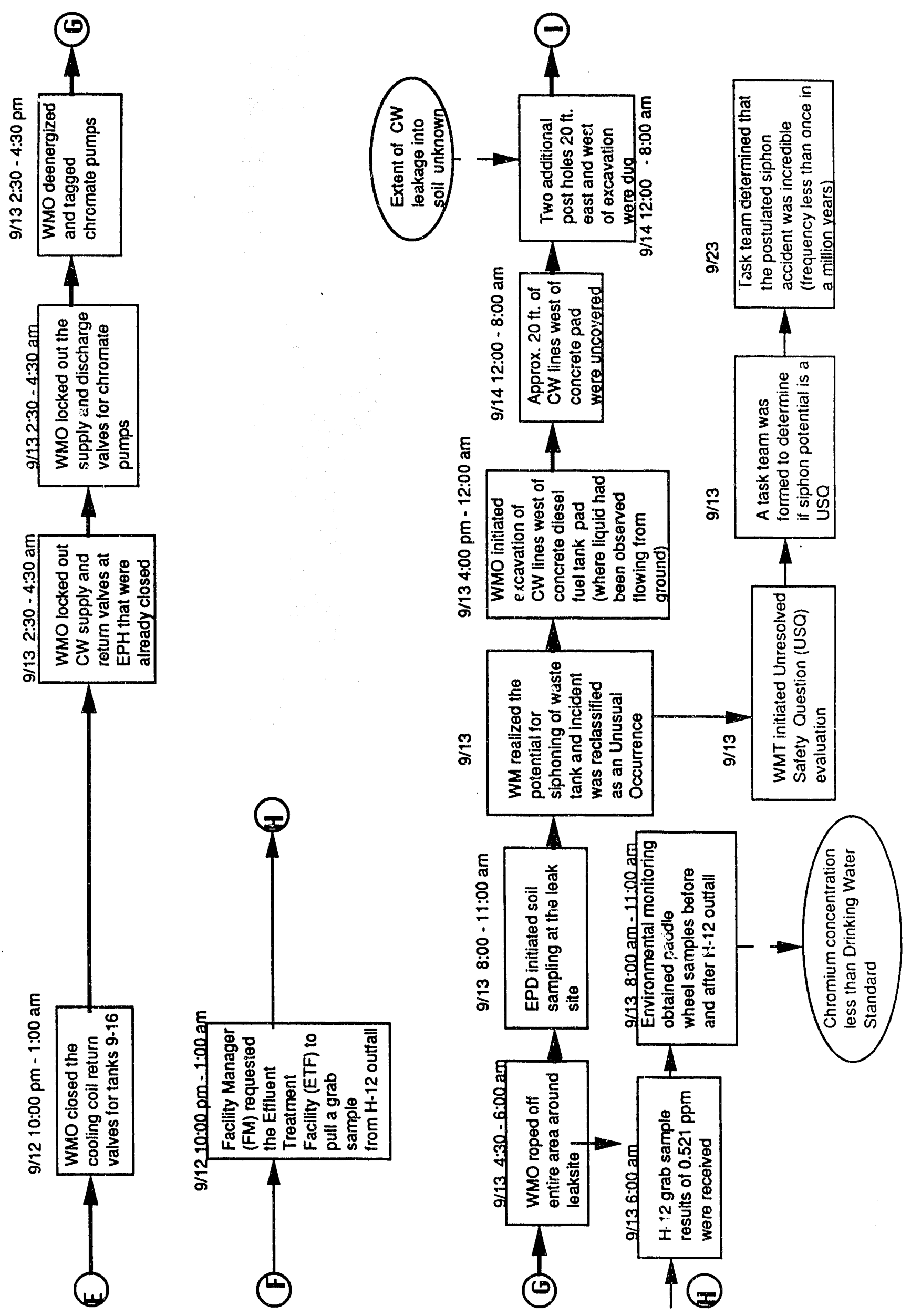
$\infty$
$\vdots$
0
0
0
0
0
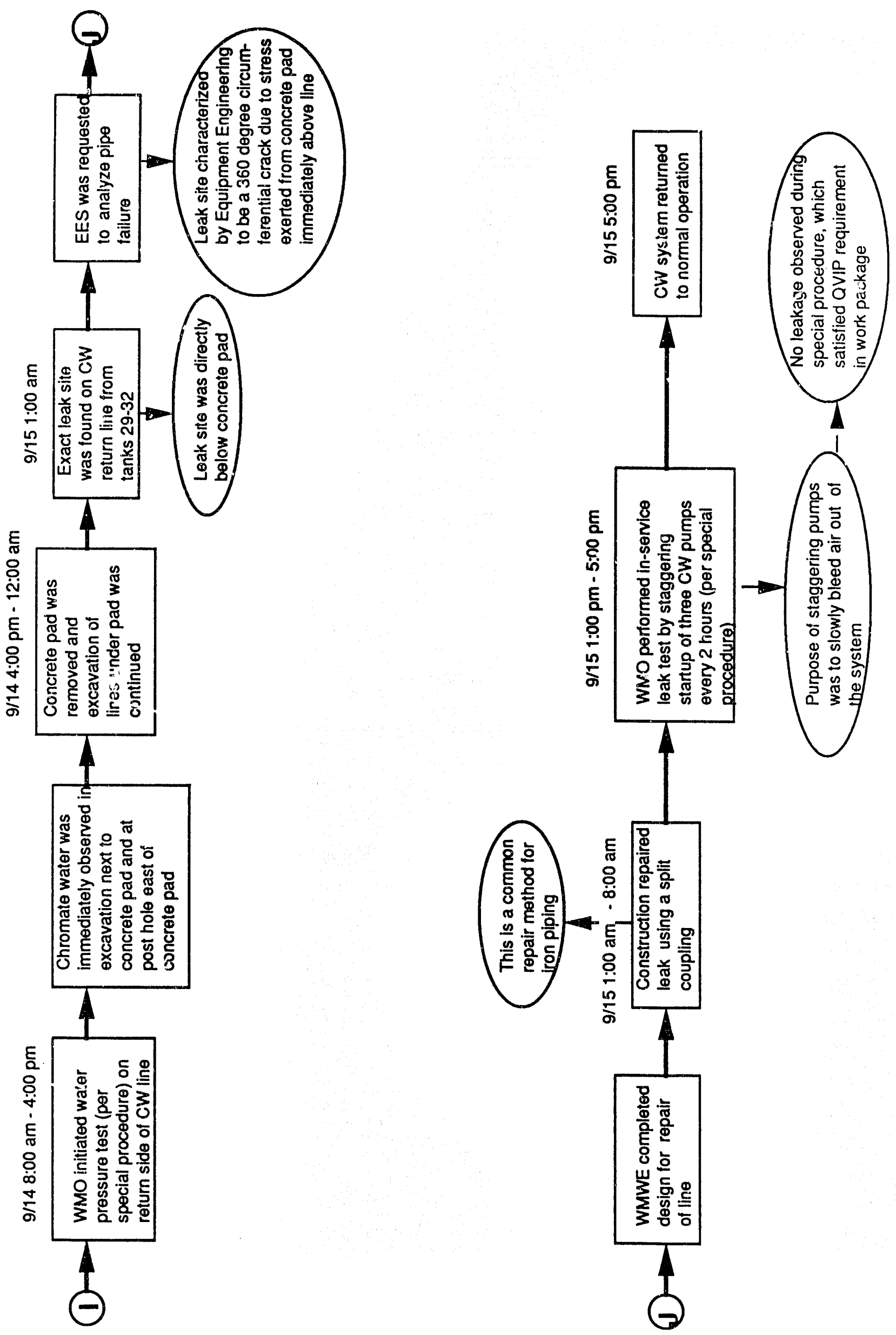
WSRC-TR-91-562

ATTACHMENT 2

NMP-WMT-910799

6 Pages 


\section{WESTINGHOUSE SAVANNAH RIVER COMPANY INTER-OFFICE MEMORANDUM}

September 16, 1991

NMP-WMT-910799

To:

B.L. Lewis, 703-H

From:

W.B. Van Pelt, 241-120H for we

Waste Tank_Cooline Systems

System Description

The tank interior cooling system is a corrosion-inhibited (with chromate in the form of $\mathrm{Na2CrO4),} \mathrm{closed-loop} \mathrm{system} \mathrm{where} \mathrm{water} \mathrm{is} \mathrm{pumped} \mathrm{through} \mathrm{tank} \mathrm{cooling} \mathrm{coils} \mathrm{and}$ returned to heat exchangers where the radiolytic heat absorbed is removed by cooled water on the shell side of the exchanger. The shell side water is provided from a separate cooling tower system located adjacent to the facility housing the heat exchangers and chromated cooling water pumps. The system is schematically presented in Figure 1.

This closed-loop system is designed to operate at a pressure greater than the head pressure of liquid waste in the tank so that a leak in a tank cooling coil submerged in waste will not pass an appreciable amount of radioactivity into the cooling water system. This differential pressure is accomplished using a surge tank at a sufficient elevation that the hydrostatic head in the cooling water system is always higher than that of the waste tanks served by that system. Five such systems exist in both $\mathrm{F}$ and $\mathrm{H}$ Area Tank Farms. These systems and the tanks they serve are given in Table 1.

Two types of cooling coil arrangements are used in type III tanks. One type, deployable or bundle coolers, are inserted through and supported from the tank roof. The other type are permanently mounted sets of two inch diameter, uniformly distributed cooling coil loops whch branch off the cooling water supply header and extend into the tank to 
a depth of approximately 32 feet. Type IIIA tanks use only the permanently installed type of cooling coils. Type I and II tanks also use the permanently installed vertical coils but in addition have some horizontal coils on the tank bottom. A summary of the type and number of the coils for the cooled tanks is given in Table 2.

In addition to water cooling of the tank interior, in type III and IIIA tanks both the exterior walls and the tank bottom are cooled by the ventilation flow through the tank annulus. The tank rests on a concrete slab which has radial grooves through which the annulus ventilation flows. Air flow can be directed through the outside annulus to cool and dehumidify the tank walls and through the center annular column and out through the grooves in the base slab to cool the tank bottom. The type I and II tank walls are cooled by annular ventilation, but they have a solid rather than grooved concrete slab under the tank bottom. [1]

\section{Current Cooling System Status}

Four of the five closed-loop cooling systems are currently operating normally. One system, the H-Area East Pump House system, is down for repair of a leaking underground cooling water return line. During the investigation of the failed line, the potential for a siphon from a tank with a failed cooling coil to the point of the undergroung line failure was recognized. A potential Unreviewed Safety Question (USQ) determination was initiated.

\section{Bisks of Not Qperating Tank Cooling Systems}

The primary risk in not operating tank cooling systems is the boiling of waste in tanks served by the cooling system. Boiling waste could result in atmospheric releases as ventilation system filters not designed for boiling waste break through. Additionally, tank corrosion chemistry cannot be maintained possibly causing leaks or deformation in the primary tarik. [2]

The potential for boiling waste is much higher in tanks containing sludge since the radiolytic heat load of sludge is higher than that of saltcake. Table 3 shows the time required for the sludge containing tanks in both $\mathrm{F}$ and $\mathrm{H}$-Area to reach a boiling point of 115 degrees centigrade. These calculations show, as expected, that sludge tanks with low total volumes heat quickly to the boiling point with no cooling. [3] 
NMP-WMT-910799

9/16/91

Page 3

A secondary concern of loss of cooling water is the increased corrosion of cooling coils themselves. Recent SRL studies have shown that stagnant cooling coils are at a higher corrosion risk due to depletion of the chromate as it forms a passivating film. This depletion rate is increased as the temperature inside the stagnant coil rises. Cooling water should be flowed through the coil to ensure that stagnant pockets are not created and so that the water can be kept cooler. [4]

References:

1. DPSTA-200-10, Supplement 18, "Safety Analysis - 200 Area Savannah River Plant Separations Area Operations Liquid Radioactive Waste Handling Facilities," August 1988.

2. DPW-86-103, Rev.1, "Operational Safety Requirements for Waste Management Operations," February 23, 1989.

3. D.J. Coon and P.J. Donahue to D.B. Jett, "Waste Tank Temperature Rise on Loss of Cooling Water," August 24, 1979.

4. R.S. Ondrejcin to D.T. Hobbs, "Inhibitors in Nuclear Waste Tank Cooling Coils," WSRC-TR-91-37, January 18, 1991. 
Table 1. Waste Tank Cooling Systems

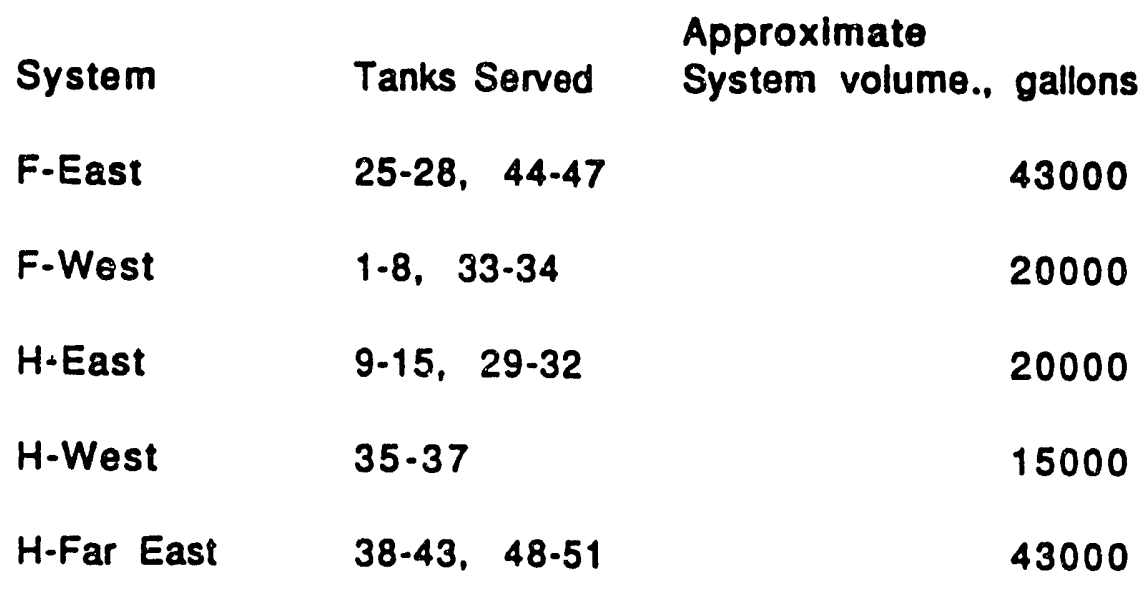


Table 2. Waste Tank Cooling Coll Information

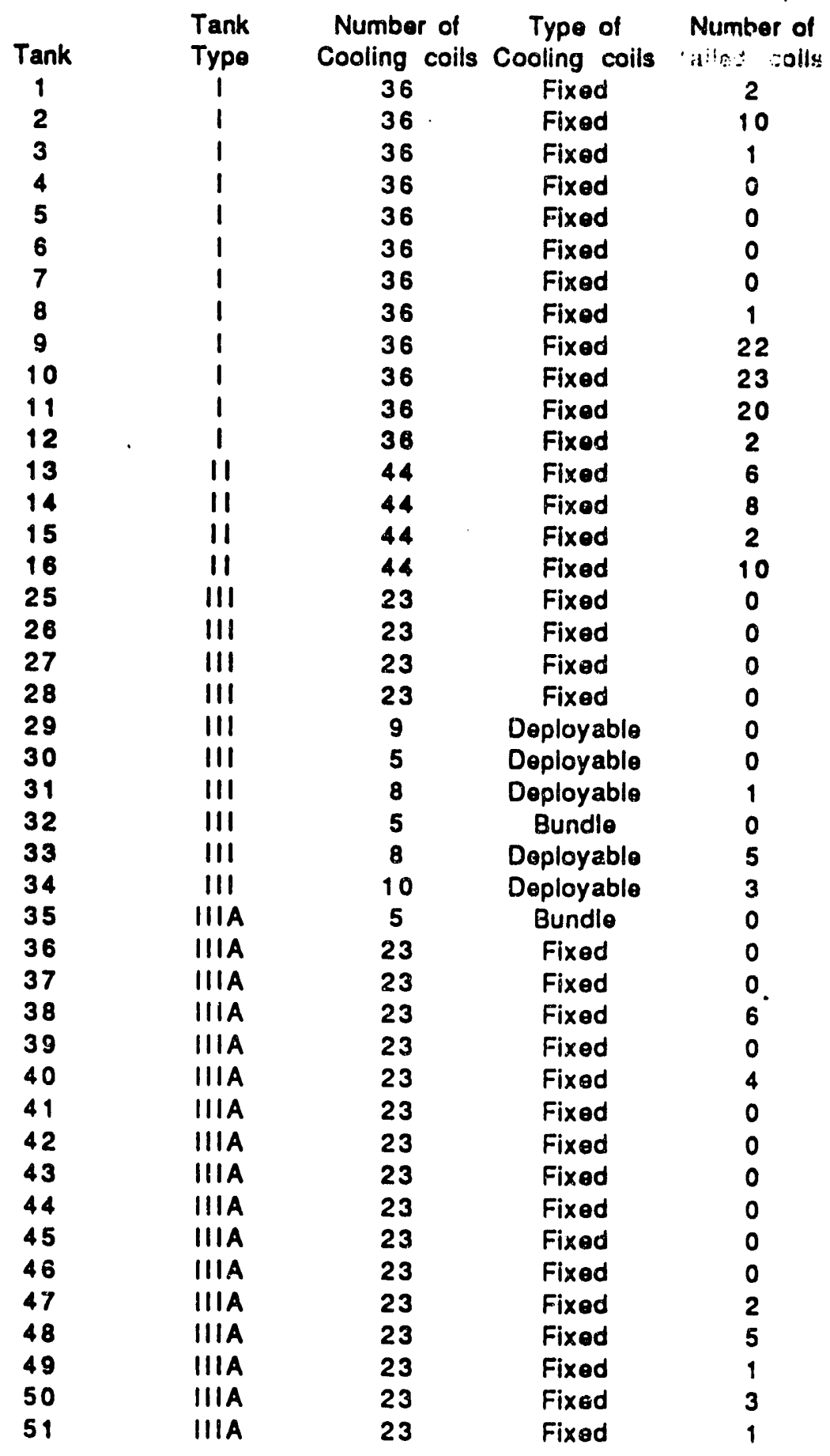




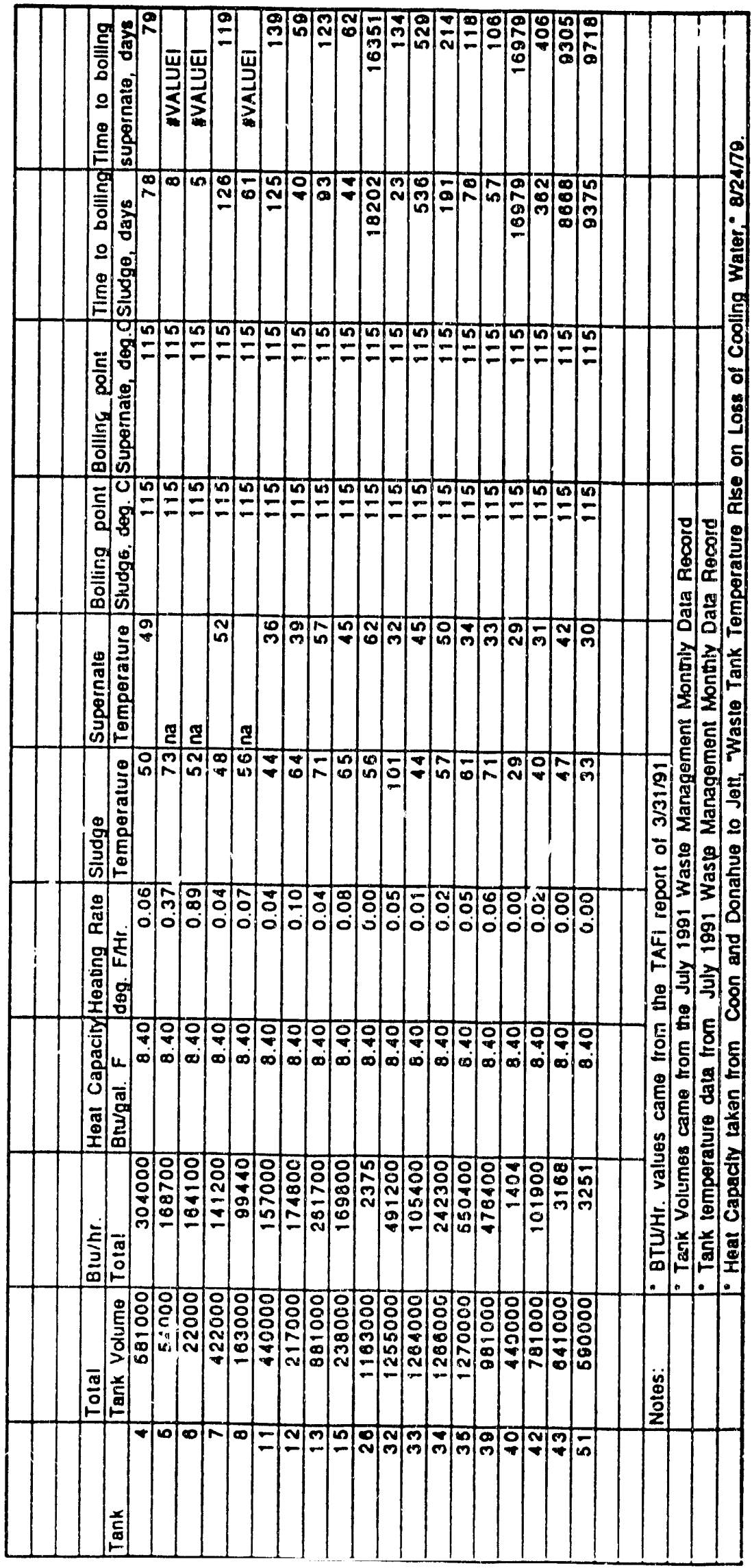




\title{
DON'T SAY IT -- WRITE IT
}

\author{
19 September 1991
}

\author{
CC: Brenda Lewis \\ Mike Chandlex \\ Mario Ceravolo \\ Bob scaggs
}

To: Ray Lux

Bill Perkins

From: P. D. d'Entremont, 703-H, 78727

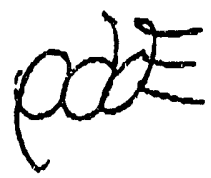

As we discussed yesterday, here are some reasonable things to assume in preparing your safety anaiysis of the tank siphon accident. These assumptions were reviewed by Brenda Lewis, Marlo Ceravolo, Bob scaggs, and Mike Rea.

\section{General}

How many tanks have the potential for siphon? 28 . Ten in $F$ area - all the type III tanks. Nineteen in $\mathrm{H}$ area - twenty-one tanks with cooling coils have maximum liquid levels that are above the level of the cooling water headers outside of tanks (all tanks except 9-12), but one is empty (16) and tank 50 has no high-level waste. The tanks with a potential for siphon are rarked on the attached sheets.

What is tho failure froguency for cooling coils? The attached pages from the "Waste Management Monthly Data Record," July 1991, show the number of failed coils in each tank.

Information about cooling watex systems.

\begin{tabular}{|c|c|c|c|c|c|c|}
\hline System & Tanks Served & $\begin{array}{l}\text { No. of } \\
\text { Tanks } \\
\text { With } \\
\text { siphon } \\
\text { pot. }\end{array}$ & $\begin{array}{l}\text { System } \\
\text { volume } \\
\text { (gals) }\end{array}$ & $\begin{array}{l}\text { Total } \\
\text { Header } \\
\text { Length } \\
\text { (feet) }\end{array}$ & $\begin{array}{l}\text { Header } \\
\text { length } \\
\text { outside } \\
\text { monitored } \\
\text { zone } \\
\text { (feet) }\end{array}$ & $\begin{array}{l}\text { Percent } \\
\text { Outside } \\
\text { Monitored } \\
\text { zone }\end{array}$ \\
\hline $\begin{array}{l}\text { F-East } \\
\text { F-West } \\
\text { H-East } \\
\text { H-West } \\
\text { H-Far East }\end{array}$ & $\begin{array}{l}25-28, \quad 44-47 \\
1-8, \quad 33-34 \\
9-15, \quad 29-32 \\
35-37 \\
38-43, \quad 48-51\end{array}$ & $\begin{array}{r}8 \\
2 \\
7 \\
3 \\
10\end{array}$ & $\begin{array}{l}43000 \\
20000 \\
20000 \\
15000 \\
43000\end{array}$ & $\begin{array}{l}1500 \\
1100 \\
8730 \\
2384 \\
2200\end{array}$ & $\begin{array}{r}690 \\
0 \\
900 \\
1228 \\
50\end{array}$ & $\begin{array}{r}46 \% \\
0 \% \\
11 \% \\
51 \% \\
2 \%\end{array}$ \\
\hline
\end{tabular}

Note: Looking at this chart, I conclude that you should analyze the H-East system, coincidentally the one that failed on Thursday. 
Page 2 of 6

19 September 1991

It has the longest header lengths (so it's the most 11kely to (ail), it has a large number of tanks, and it has 118 of the header out of the monitored storm watex zones.

How long does it take to isolate a cooling header leak? About 3 hours. As a result of our discussion with you yesterday, we are revising the procedure to require that all tanks in a cooling system be isolated from the system when a header leak occurs of sufficient size to cause pressure to be lost in the system. (If the leak is so small that we can maintain pressure, we don't have the potential for a large siphon).

The current procedures (241-H-903 and 241-F-903) require only that the return valves at each tank be closed as soon as the leak is discovered. We axe revising those procedures now, so you can assume the 3 hours for your analysis.

Large siphon Accident (i.e. catastrophic break both in a cooling coil and in the cooling header below the level of the waste)

How long would it take to stop a large siphon by turaing of the beeder valves at the tank? 4 hours (Brenda's estimate). This assumes that the pipe is full of high-heat waste and is radiating in excess of $100 \mathrm{R} / \mathrm{hr}$. For a small leak that radiates only in the $\mathrm{mR} / \mathrm{hr}$ range, we could shut it off more quickly.

After a break in the cooling neader, do we turn off the ssolation valves at each tank? Yes. See answer above. Assume a maximum of thres hours vulnerability from the time a large header leak occurs.

Small Siphon Accident (1.e. typical leak in cooling coil followed by a catastrophic break in a cooling header)

That is a typical, laxge cooling coil leak? According to Neil Davis, the largest leak that he can recall is about 250 gallons per day. Most leaks are less, 50 to 100 gallons per day, according to Mike Rea, so 250 seems like a good number to use for an analysis. According to Dworjanyn, a leak that allowed 250 gallons per day to leak when the system was operating (at 90 psi), would siphon at about 100 gallons per day, assuming a 40 foot elevation aifference between the liquid level and the location of the header leak, and assuming a large header leak. 
Page 3 of 6

19 September 1991

How long to flnd and valve off a small cooling coll leak? Assume 7 days. Actually, we usually notice that a leak is happening in a day, and then valve it off in another day, i.e. two days total. seven days is a conservative number.

What would the consequences be for a small giplon acoident? About 15 gallons would be released into the cooling water system. From Dworjanyn, above, a conservative siphon rate would be 1.00 gallons per day. since we'd isolate the tanks within three hours arter the header depressurized, that's the maximum length of time that the siphon would occur.

since the smallest cooling system has 15,000 gallons in it, the 15 gallons would be mixed with a considexable amount of cooling water, and so even if a large amount of water wexe released from the header, say 1000 gallons, that would contain only a small fraction of high-heat waste. I think a conservative value would be that 1 gallon of high-heat waste would escape the header. 


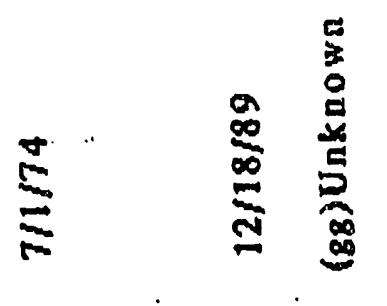

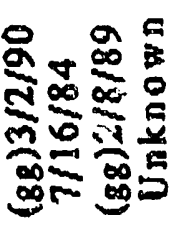

$n-m-$

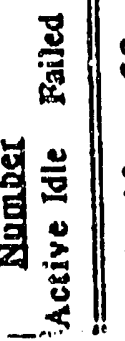

ำ

mor

$m E=N$ Non

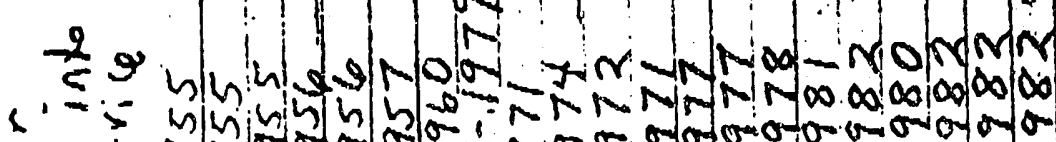
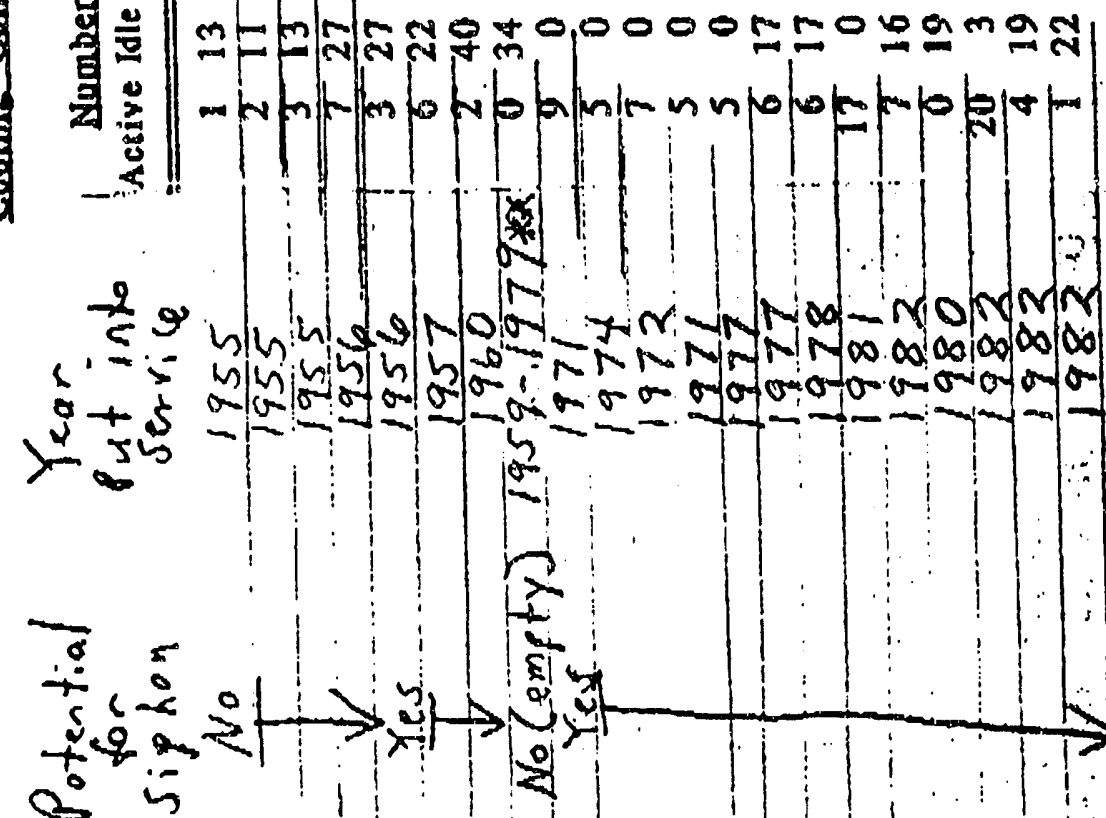

peter
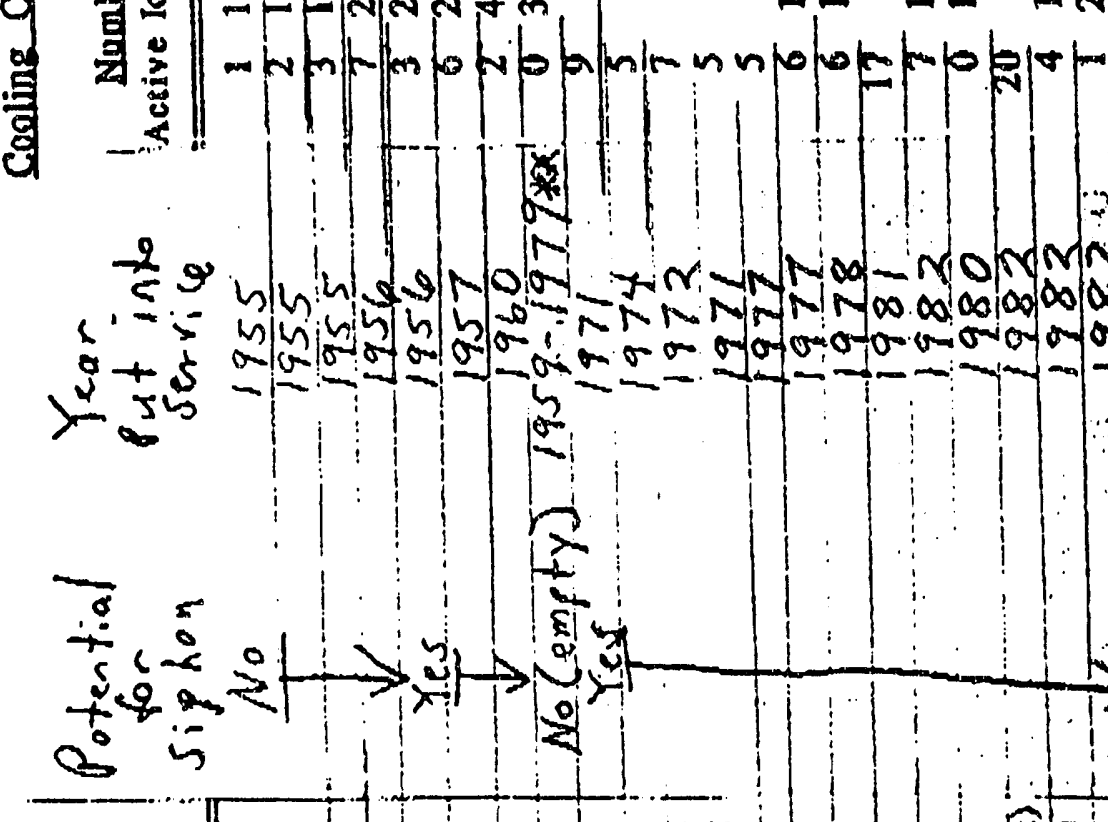

क

勿

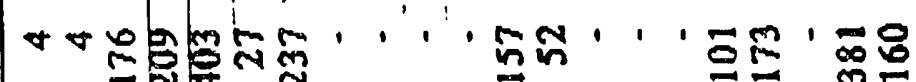

으의

ทั

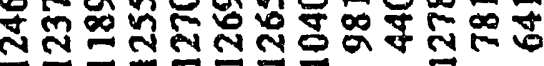

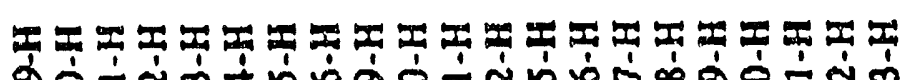

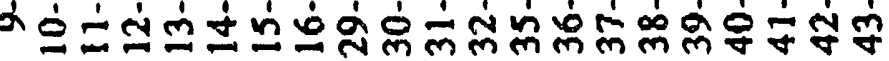

|

doisios

$\infty, 0-i, 0$

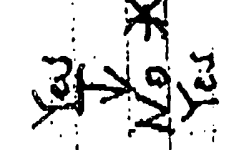

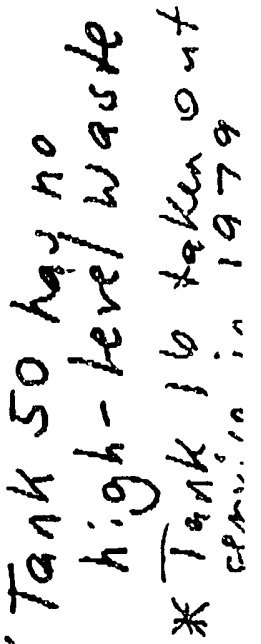

*
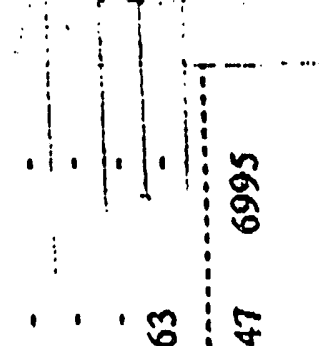

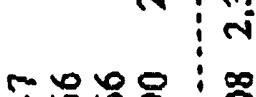

능요용

푼

安守它向 : 


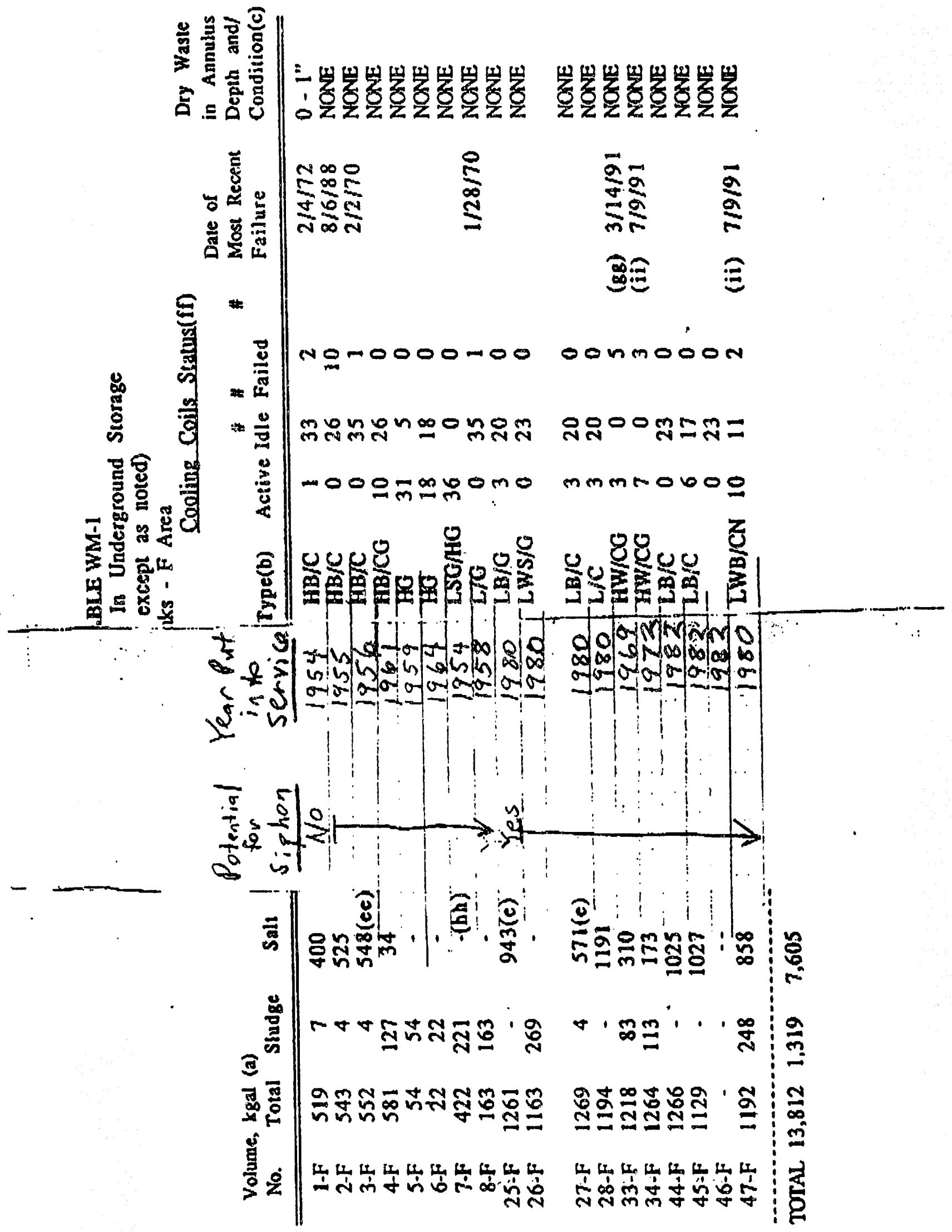




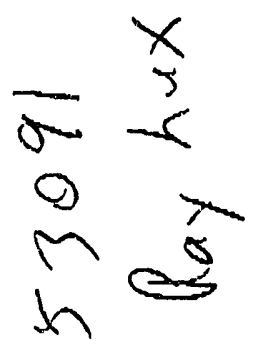

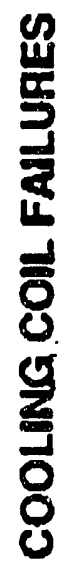

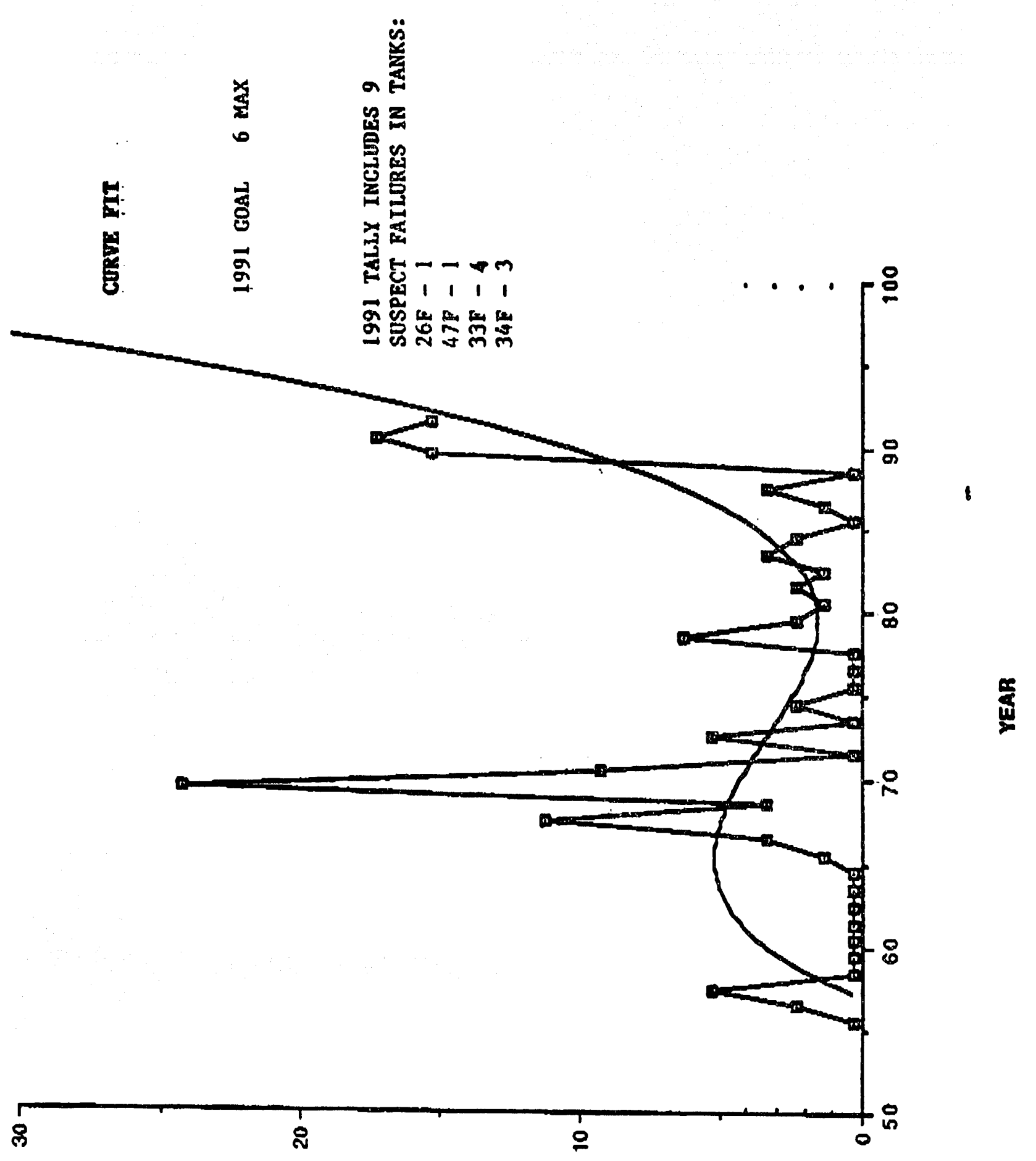


WSRC-TR-91-562

ATTACHMENT 4, 14 Pages

Westinghouse Savanaah River site
Inter-Office Memorandum

September 19,1991

TO: R. W. Wilson, 703-H

V. G. Dickert, 703-F

FROM: M. J. Rea, 241-147H (x7-1796).MrR

R. E. Nordstrom, 241-102F (x2-3354) REN Gy MTR

H/F - Area Pumphouse surge Tank Level Profiles

Background

The tank interior cooling system is a corrosion-inhibited, closed-10op system where water is pumped through tank cooling coils and returned to heat exchangers where the radiolytic heat absorbed is removed by cooled water on the shell side of the exchanger. This closed-loop system is designed to operate at a pressure greater than the head pressure of liquid waste in the tank so that a leak in a tank cooling coil submerged in waste will not pass an appreciable amount of radioactivity into the cooling water system. This differential pressure is accomplished using a surge tank at a sufficient elevation that the hydrostatic head in the cooling water system is always higher than that of the waste tanks served by that system. Five such systems exist in both $\mathrm{F}$ and H-Area Tank Farms.

\section{Discussion}

In order to analyze the performance of each pumphouse surge tank, the last $\mathbf{s i x}$ months of level data was collected and plotted (see attached graphs). Also, the chromated water activity (sampled weekly) was plotted to determine if waste tank cooling coil failures correlate with increased activity in the cooling water. After reviewing the data, it appears that the surge tank level is an adequate means for determining leaks in the chromated cooling water system. By monitoring the surge tank level daily, small leaks ( 30 gallons/12 hour shift) in the system will, be detected, then reported to process supervision, and investigated per Procedure $24 \mathrm{I}-\mathrm{F} / \mathrm{H}-703$.

However, some routine instrument level fluctuation occurs, as seen in several of the graphs. This is normally due to thermal expansion and contraction of the cooling water in 
the system as well as some level transmitter drift. The following unexplained level changes were found to exist:

1) H-Far East Surge Tank

From June 1st to september 15, no cooling coils were found to be leaking, yet the surge tank level

fluctuated more than normal. Possible causes are level instrumentation problems or a slow leak in the cooling water system (e.g. valves, fittings). See recommendations 7 and 8 .

2) F-West and F-East Surge Tanks

The abnormal surge tank level fluctuations are unexplained. It appears that there is a slow leak in each cooling water loop. See recommendations 7,8 , and 9.

From the graphs, we conclude that there isn't a good correlation between the time a cooling coil leak is found and the magnitude of the chromate water activity. This indicates there is normally sufficient pressure in the failed coil to prevent migration of waste into the circulating cooling water or that the leak did not occur in the submerged portion of the coil. As stated previously, the pressure in the failed coil will be maintained either by the recirculation pump or in the event that the pump fails, the head pressure supplied by the liquid in the surge tank.

As expected, the F-East, H-West, and H-Far East chromate water activities were relatively low with a few notable spikes. These spikes are a long term condition, and according to the $772-\mathrm{F}$ lab, can be attributed to the varying background levels in the lab where the low activity samples (obtained weekly) are analyzed. The H-East and F-West systems have always had higher levels of gamma activity, most likely due to the greater number of previously failed cooling coils on these loops (all failed cooling coils are isolated).

WMT recommends that the following items be completed to provide more controlled monitoring and trending capabilities of the surge tank level and chromate water characteristics:

1) Update the WMT surveillance database to include all pumphouse surge tank levels, chromate water activities, chromate concentrations, and chromate water pH. These parameters will be graphed once/month by the WMT surveillance and Monitoring Group and included in the first weekly oversight Update report of the month compiled by $W$. R. West.

(WMT - F. J. Riddle) 
2) Add a section in the operating runbooks to record the surge tank level once/hour for surge tanks that have level recorders in the control room and once/shift for surge tank levels that are read in the pumphouse. (WMT - M. J. Rea, R. E. Nordstrom)

\section{current status:}

H-East - stripchart in pumphouse, read once/shift

$\mathrm{H}$-West - stripchart in control room, read once/shift $\mathrm{H}-\mathrm{FarEast}$ - stripchart in control room, read once/shift F-East - stripchart in control room, read once/shift

F-West - stripchart in pumphouse, read once/shift

3) For surge tanks that have level readouts in the pumphouse, relocate the level recorder to the control room and revise the operating runbooks per $\# 2$ as the work gets completed. (WMT - M. J. Rea, R. E. Nordstrom) (WMO - R. W. Wilson, V. G. Dickert)

4) Revise the operating runbooks to include a section to. record the amount of well water added to the surge tarik during each shift.

(WMT - M. J. Rea, R. E. Nordstrom)

5) Revise the morning report to include a space for recording the amount of well water added to each surge tank each day. (WMO - W. L. Barnhill, L. C. Thomas)

6) Continue development of the T\&R Procedure for completing the morning report, and include the provision from $\$ 5$. (WMT - R. E. Nordstrom)

7) Perform loop verifications on the H-Far East, F-West, and F-East surge tank level instrumentation to ensure accuracy.

(WMWE - J. L. Brown, W. A. Morrison)

8) For the H-Far East, F-West, and F-East systems, WMO will valve off all cooling coils that lost 2 psig or more during the recently performed cooling coil pressure tests and WMT will trend the surge tank levels for 2 weeks. This is needed to better determine if these small pressure losses are a result of the testing methods, or are very small leaks in the system.

(WMO - W. I. Barnhill, L. C. Thomas)

(WIT - M. J. Rea, R. E. Nordstrom) 
9) For the F-East and F-West systems, determine if a more reliable means for measuring the surge tank level is needed (e.g. dip tubes). [Note: The instruments in all H-Area surge tanks have been replaced with dip tubes within the past 3 years.]

(WMT - R. E. Nordstrom)

10) Continue to fill the surge tanks manually (the surge tanks are designed to be filled automatically, but are currently being filled manually due to several surge tank crerflows). If the decision is made to allow the surge ank to automatically fill, it is recommended that an in-line totalizer be installed on each surge tank fill line and a readout (total gal.lons used) be located either in each control room or in each pumphouse. With this modification, the amount of water added to the system in the event of a cooling water leak will be more accurately quantified.

Since the operator will have to respond to a surge tank low level alarm by going to the pumphouse to investigate, WMT feels it is desireable to operate the surge tank fill valves manually (as is being done now). For example, if a chromate pump seal is leaking, the operator can simply valve out the leaking pump, place the spare pump on line if available, and refill the surge tank at that time. The control room operator can then record the amount of water added to the surge tank by referring to the tank calibration chart located in each control room. If by chance the surge tank has to be refilled more than once per shift, tire operator should note this in the operating runbook and include this information in the morning report.

cc:
G. T. Wright, 703-H
R. W. Harral, 703-H
S. S. Cathey, 703-H
T. M. Osborne, 703-H
N. R. Davis, 241-120H
R. A.-Scaggs, 703-H

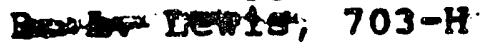
P. D. d'Entremont, 703-H
M. A. Ceravolo, 703-H
W. B. Van Pelt, 241-120H
C. G. Kelly, 703-H
M. J. Mahoney, 707-H
W. L. Barnhill, 703-H
L. C. Thomas, 703-F
M. C. Chandler 703-H
F. G. MCNatt, 704-8H
T. B. Caldwell, 703-H
J. E. Murdough, 241-100F
D. C. Blair, 241-28H

J. F. Walker, 241-28H

P. W. Norris, 241-147H

J. E. Griffiths, 241-100F

H.. E. Phillips, 241-120H

D. L. Fish, 773-A

I. O. Dworjanyn, 779-2A

W. R. West, 704-8H

G. A. Crouser, 703-H

T. Temple, 703-H

WMT File code 175.1.1, 703-H 


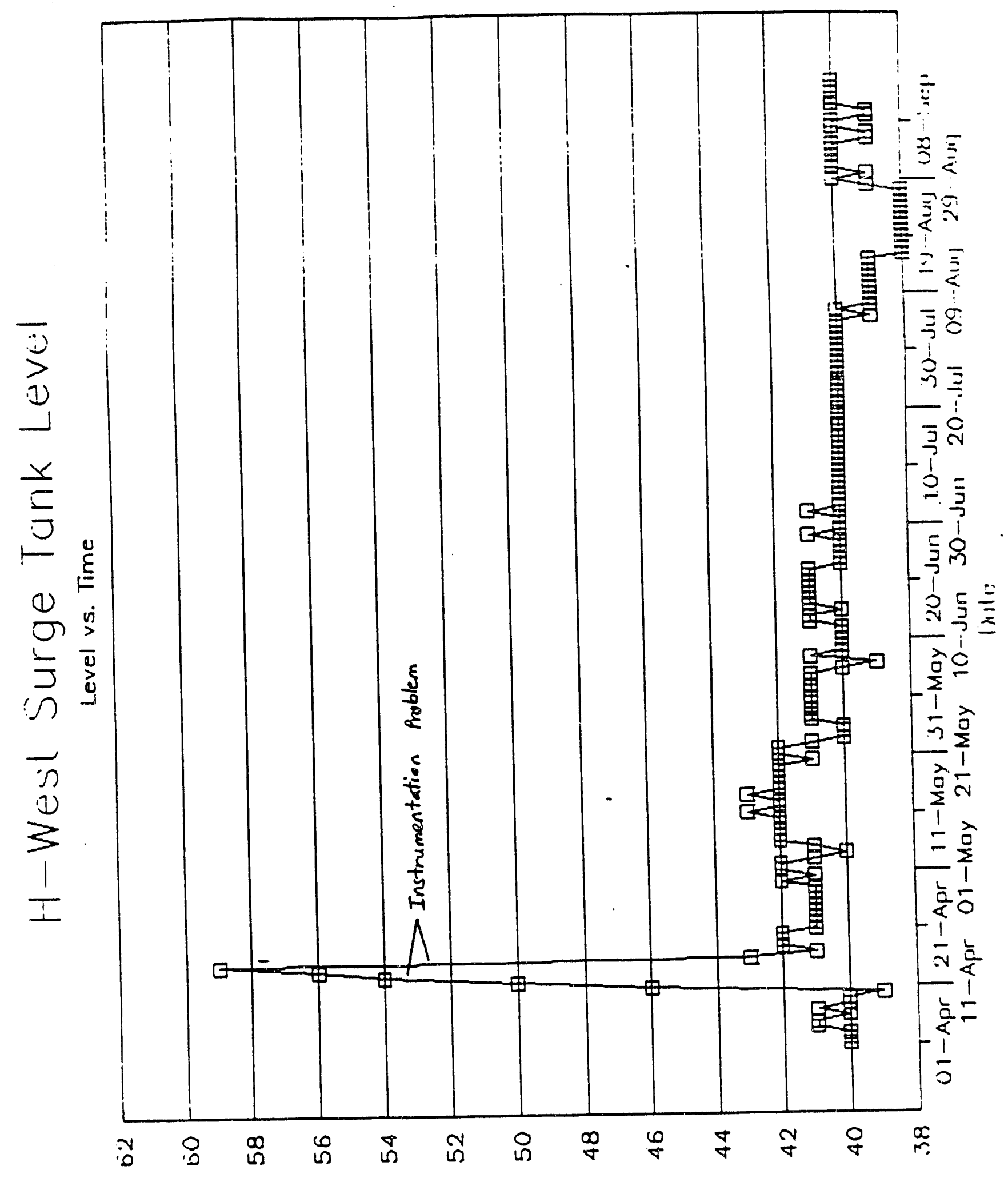

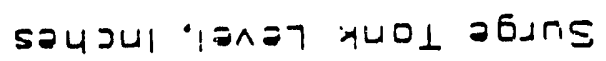




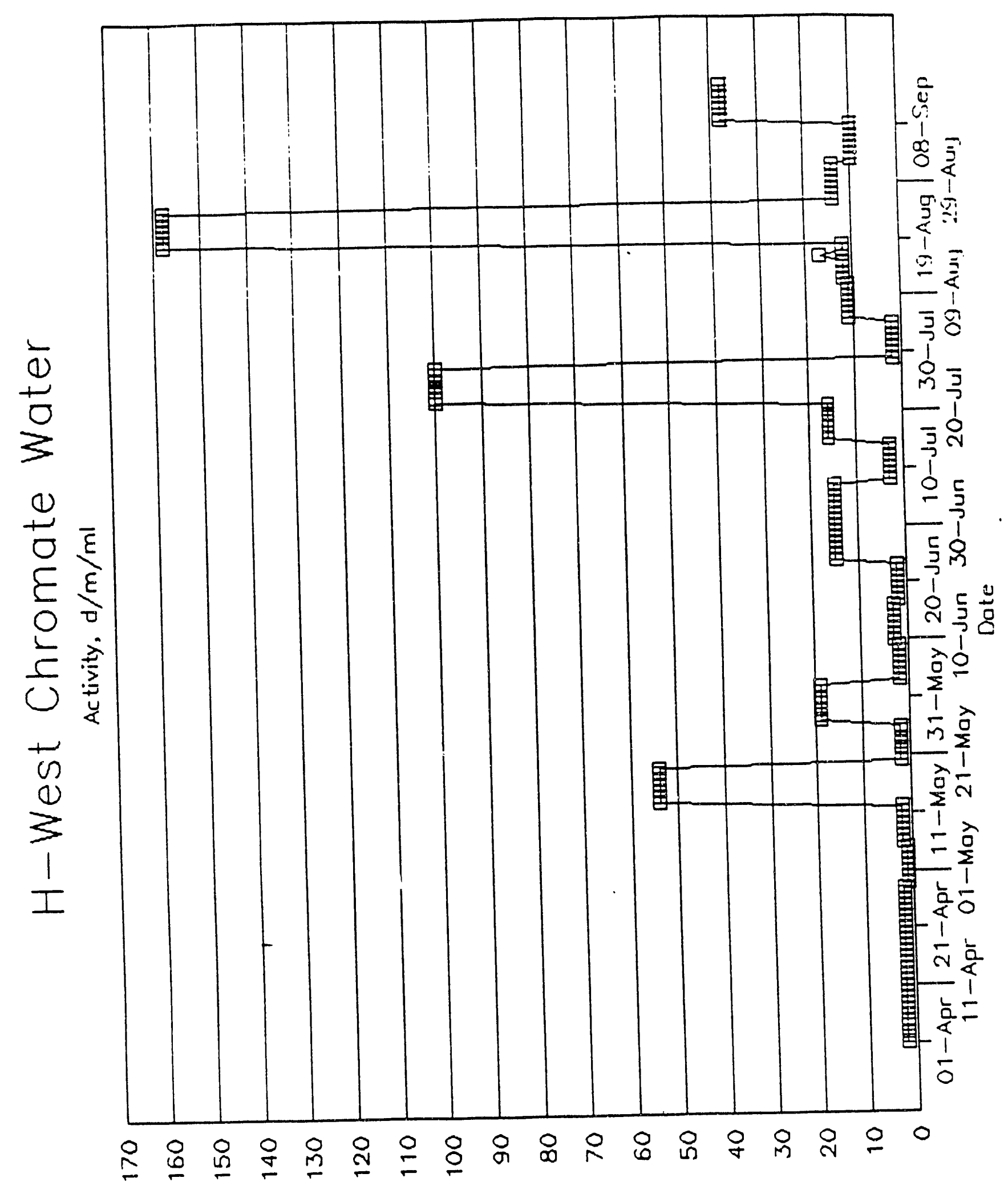

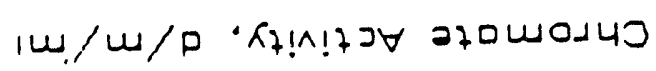




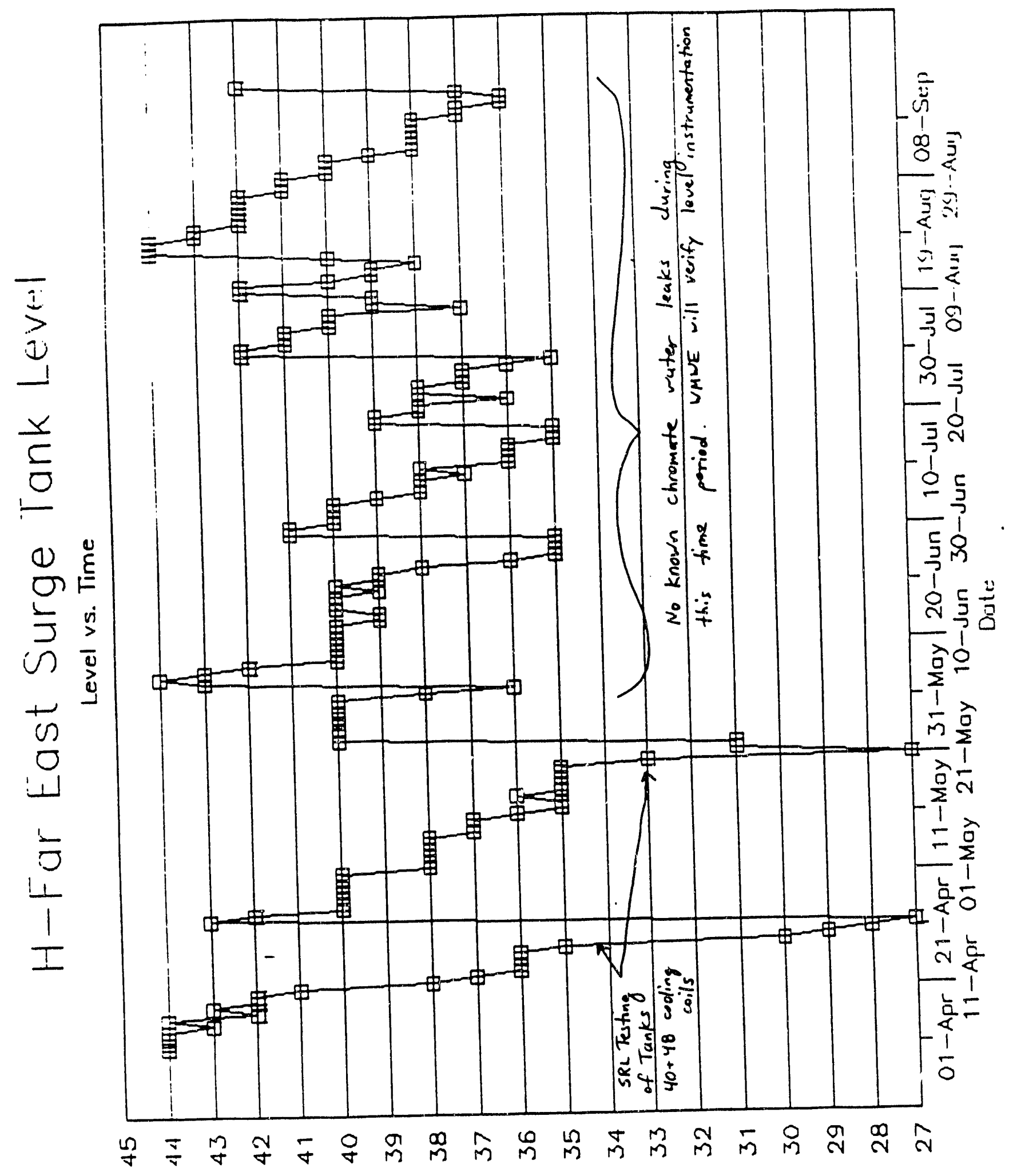




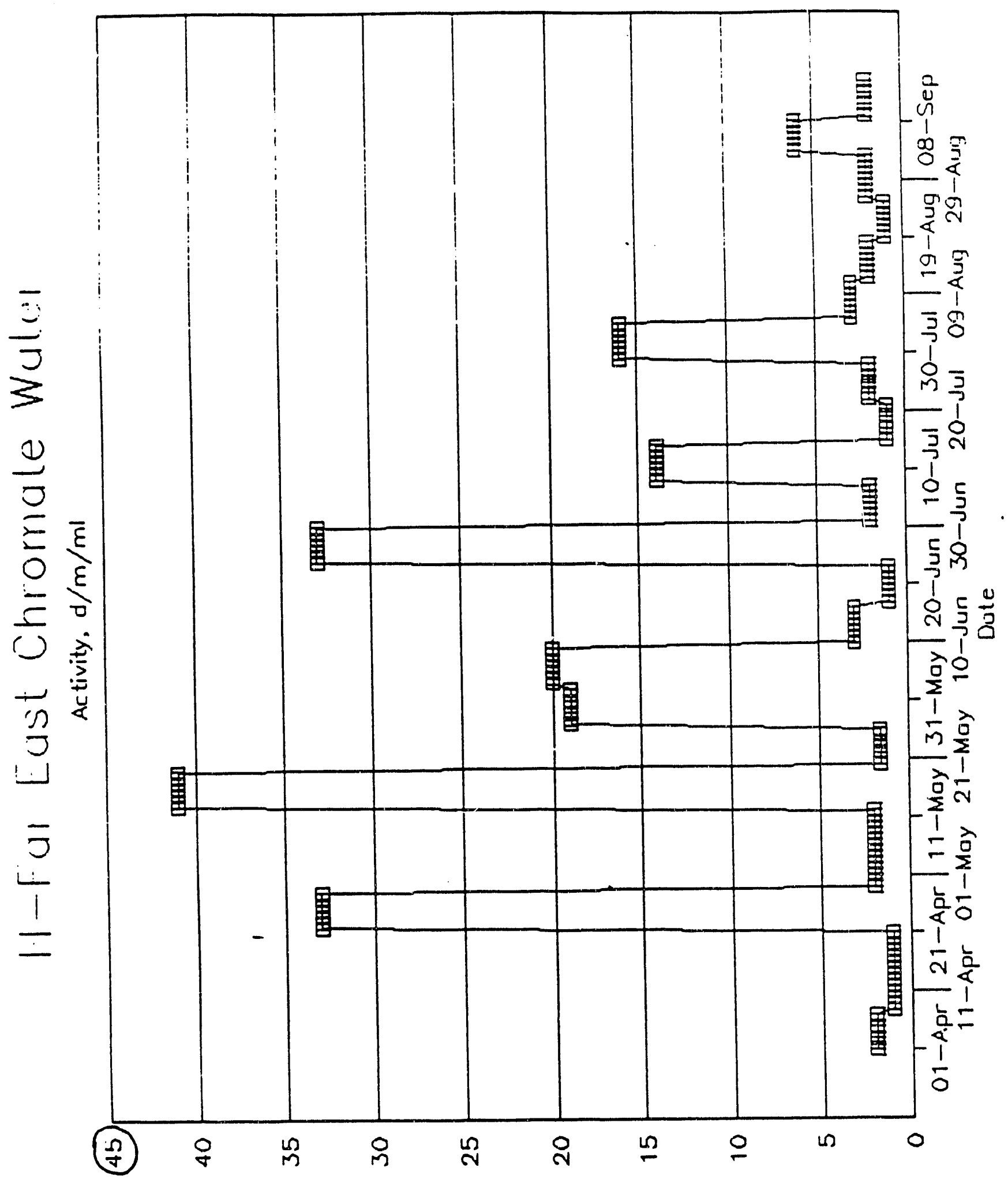

lw/w/p • 


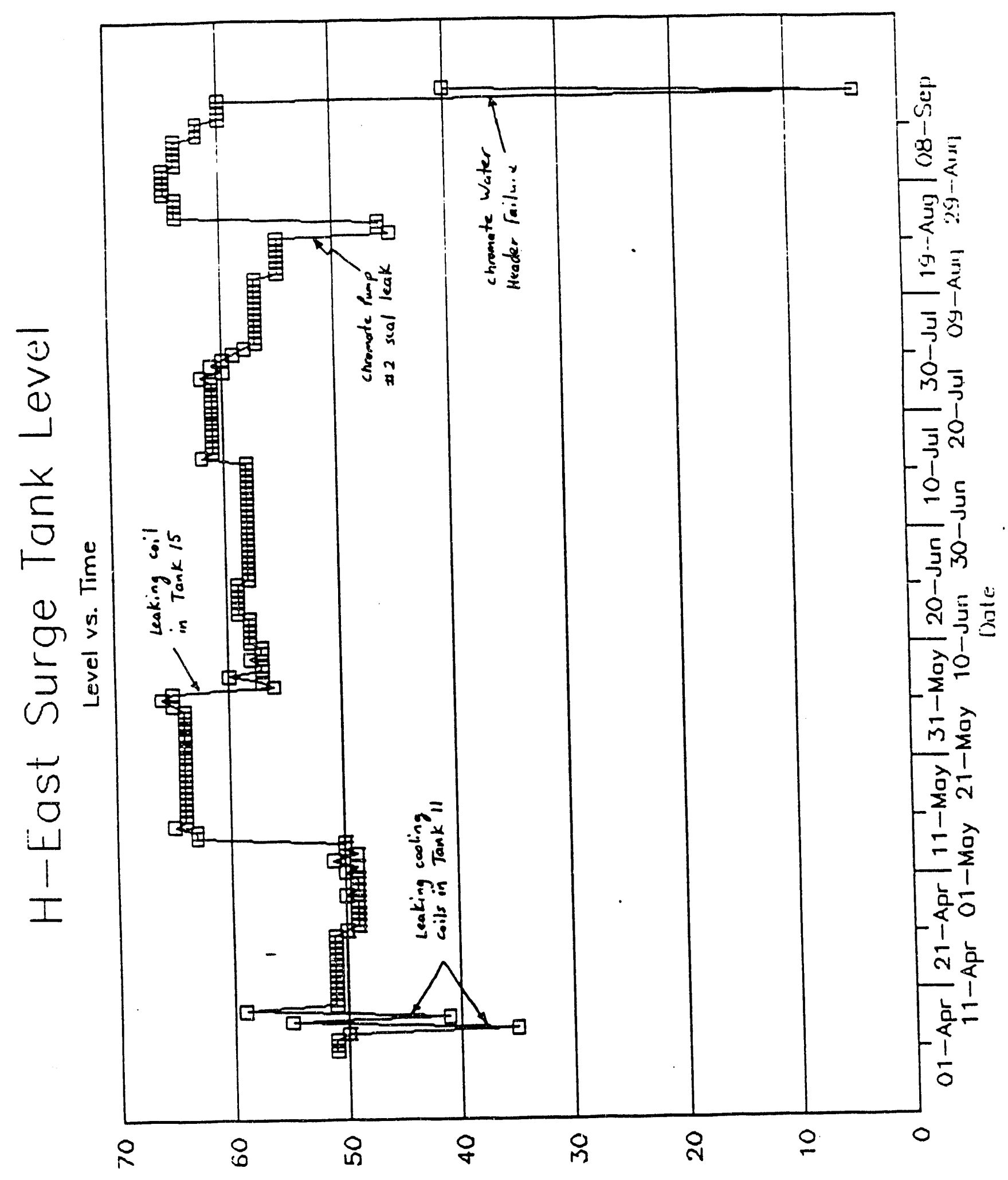


$\therefore \therefore$

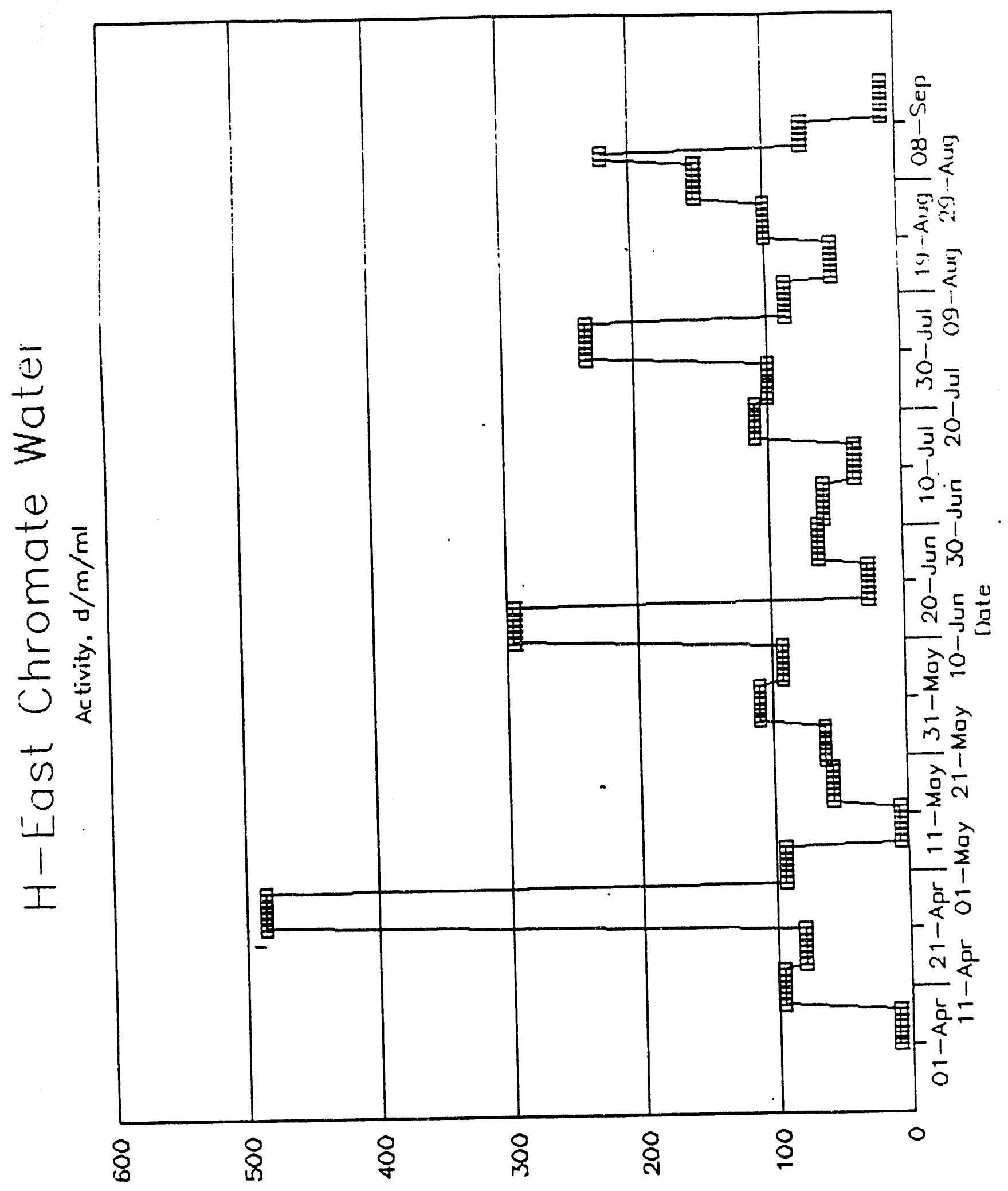

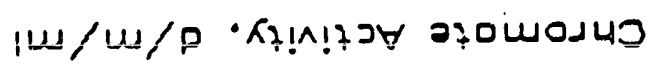




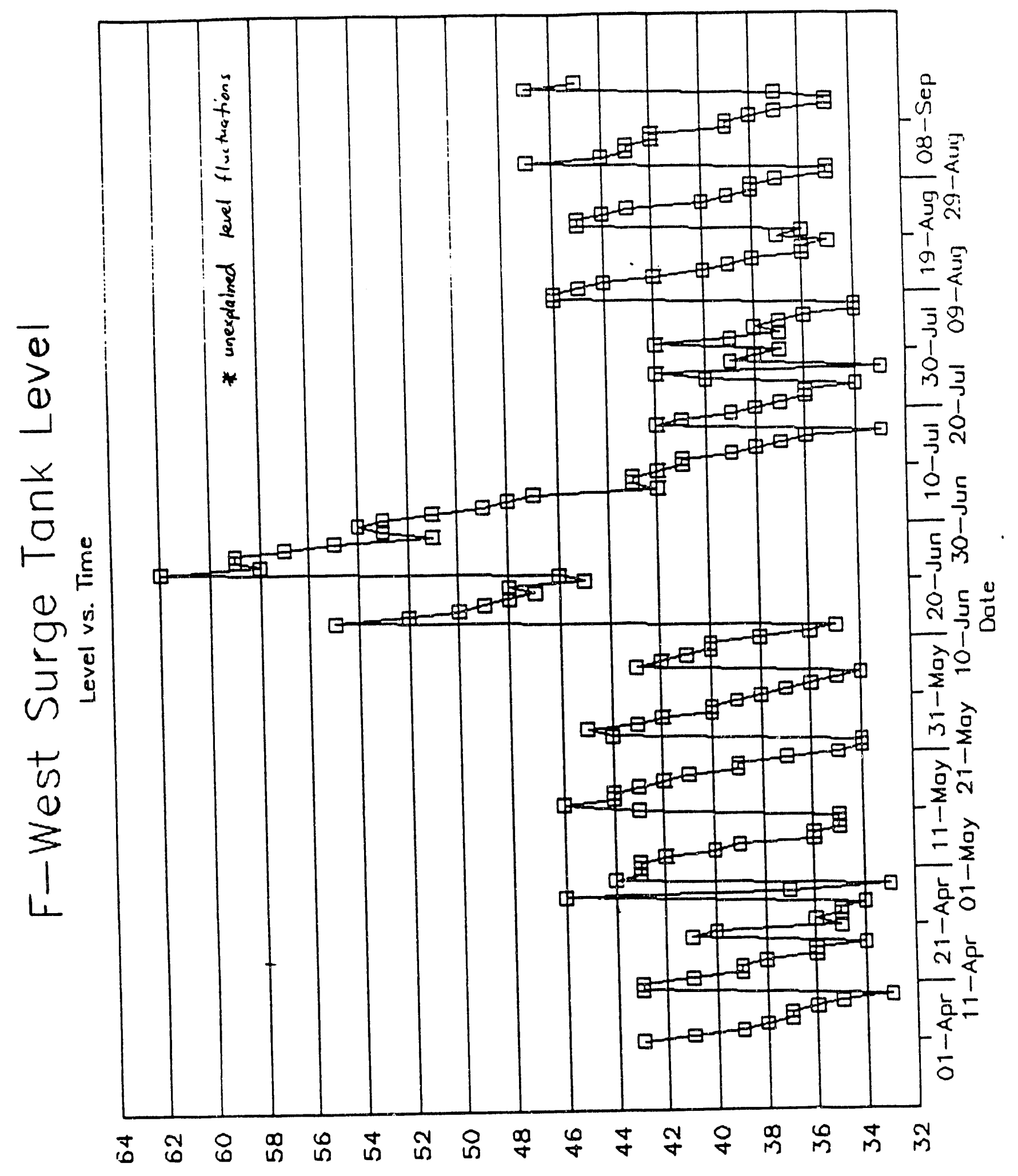

səuगU • 


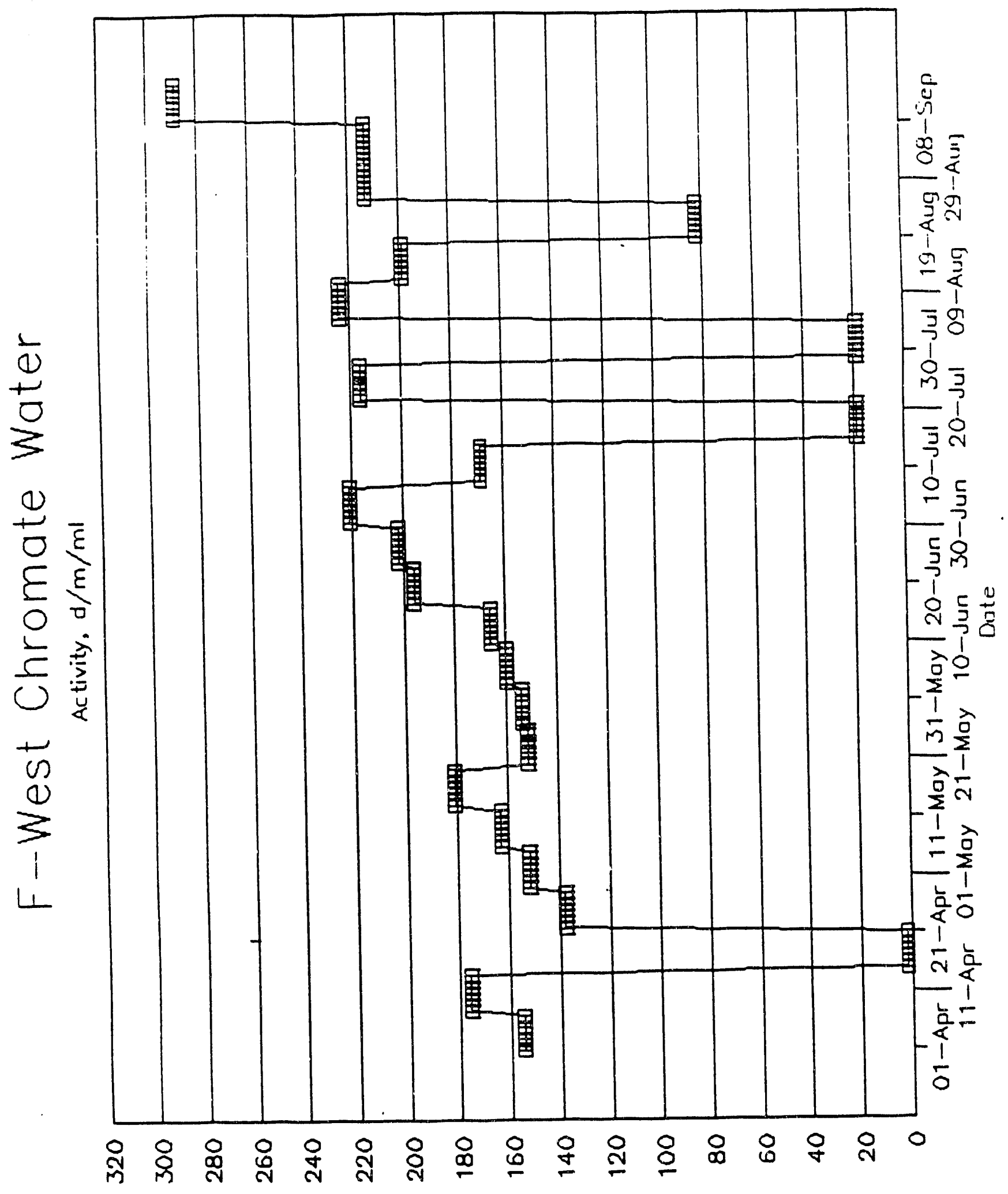




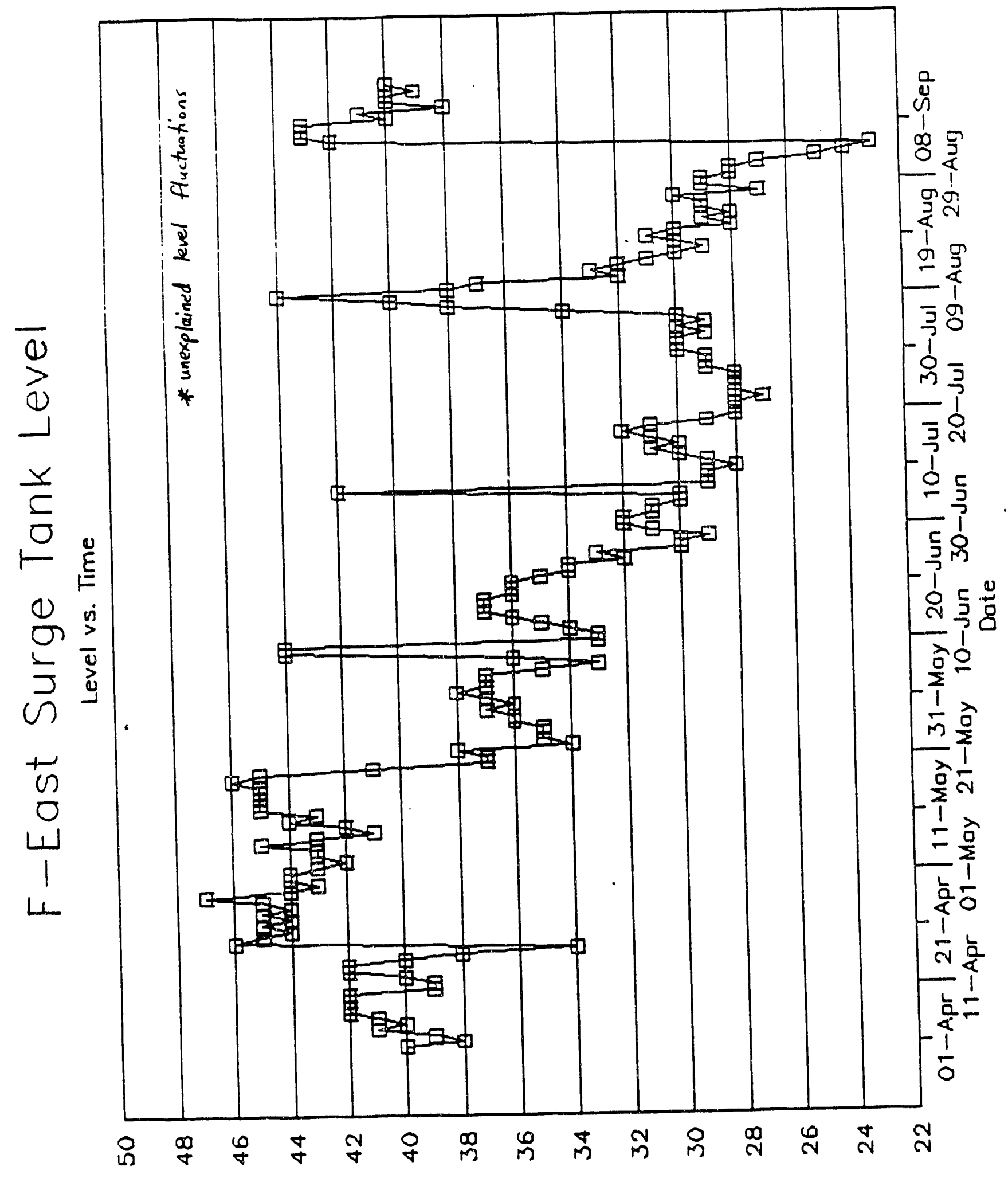




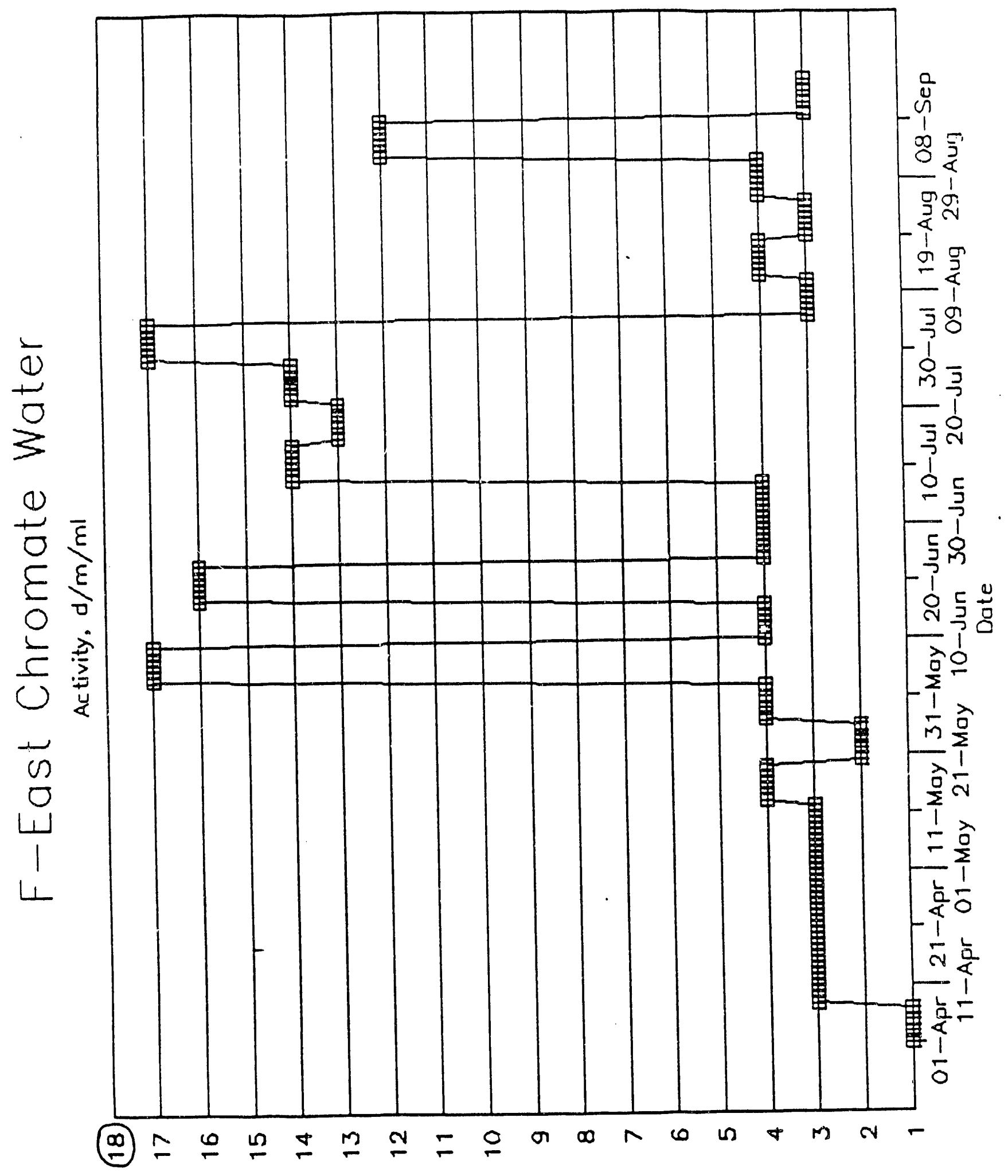



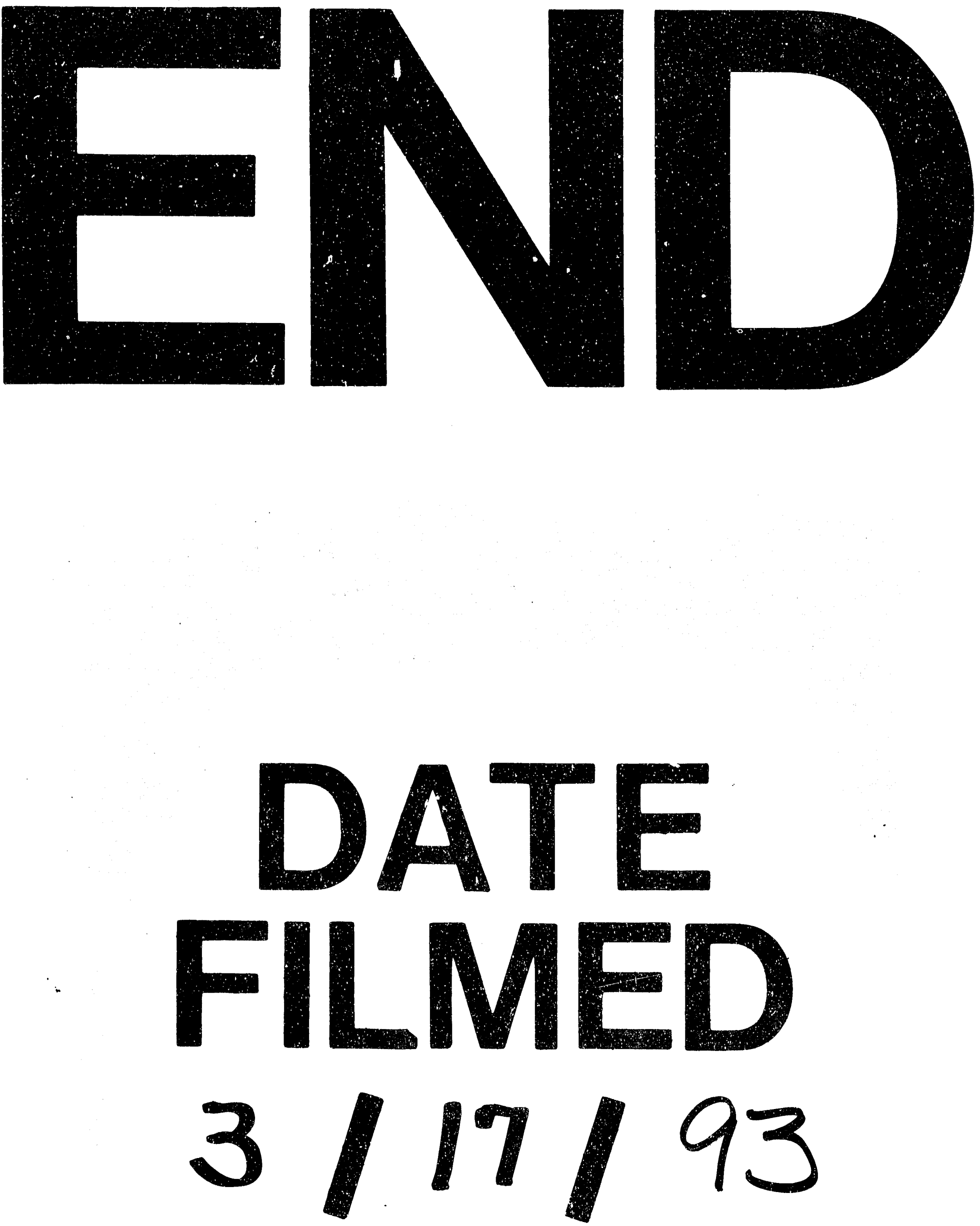
